"This is the peer reviewed version of the following article: Microalgal Phycocyanin Productivity: Strategies for Phyco-Valorization, which has been published in final form at https://doi.org/10.1002/jctb.4796. This article may be used for non-commercial purposes in accordance with Wiley Terms and Conditions for Self-Archiving. "

\title{
Microalgal Phycocyanin Productivity: Strategies for Phyco-Valorization
}

[Short Title: Microalgal Phycocyanin Productivity for Phyco-Valorization]

Nicolas Querques ${ }^{1}$, Mercedes Cesta ${ }^{1}$, Rafael M. Santos ${ }^{2}$ and Yi Wai Chiang ${ }^{1 *}$

${ }^{1}$ University of Guelph, School of Engineering, 50 Stone Road East, Guelph, Ontario, Canada, N1G $2 W 1$.

${ }^{2}$ Sheridan Institute of Technology, School of Applied Chemical and Environmental Sciences, 7899 McLaughlin Road, Brampton, Ontario, Canada, L6Y 5 H9.

* Corresponding author: chiange@ uoguelph.ca (Tel. +1-519-8244120; Fax. +1-519-8360227).

\section{Abstract}

Phyco-valorization is the exploitation of microalgae and microalgal chemicals as valuable products. This paper discusses the optimization of microalgal bioreactor-based systems for Cphycocyanin pigment production. Various aspects contributing to system development and enhancement of phycocyanin productivity are described. A wide range of potential microalgal species have been identified for phycocyanin production; the selection of a species for mass culturing can be determined by desired bioreactor trophic mode and symbiotic relations. Research has demonstrated that species amenability to local lighting and climatic conditions, and to variations in bioreactor substrate concentrations and operational parameters, have significant impact on phycocyanin production. The simultaneous optimization of all factors contributing to system productivity may be efficiently accomplished through process modelling. A summary of established models for microalgal phycocyanin production is presented. A suggested strategy for increasing economic viability 
of phycocyanin production systems is their application in integrated resource recovery. Through the incorporation of phycocyanin productivity optimization principles within a phycoremediation process, the valorization of waste resources may be achieved. The simultaneous economic potential and environmentally-forward concept of phyco-valorization through phycocyanin production is a promising application of microalgal biotechnology awaiting further development for industrial implementation.

Keywords: Phycocyanin; Integrated Resource Recovery; Microalgae Bioreactor Optimization.

\section{Contents}

Nomenclature

Introduction

Applications

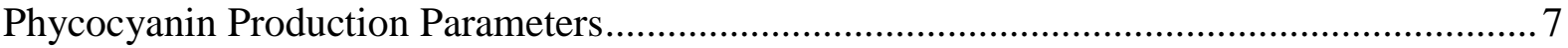

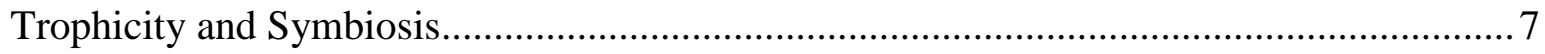

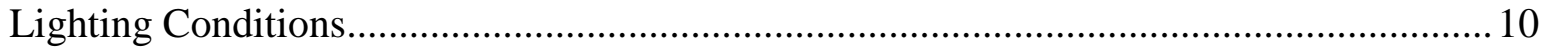

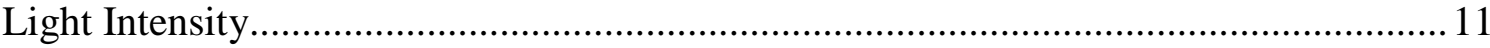

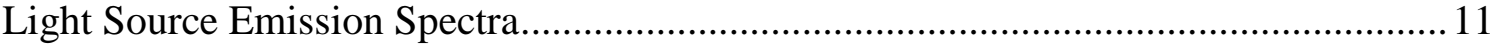

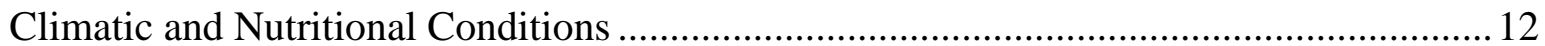

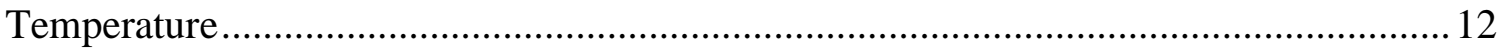

$\mathrm{pH}$

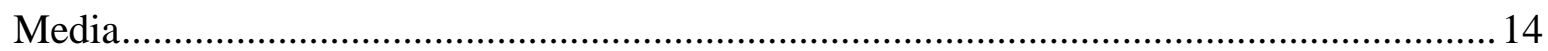

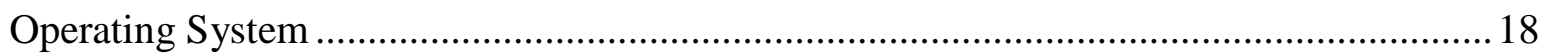


Phycocyanin Production Modelling.....

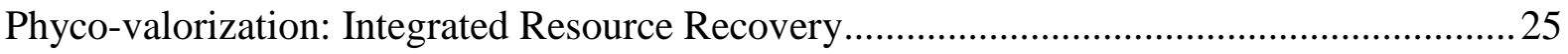

Reaching Optimal Production Parameters via Phyco-valorization .....................................2 27

Lighting Conditions for Phyco-valorization ............................................................ 27

Climatic and Nutritional Conditions for Phyco-valorization ........................................22

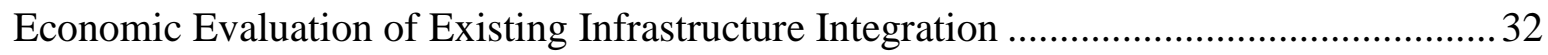

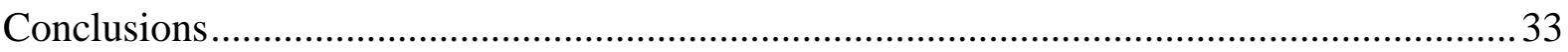

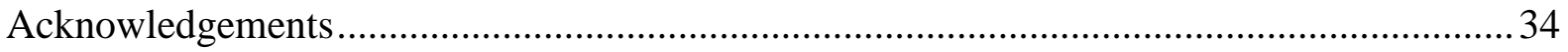

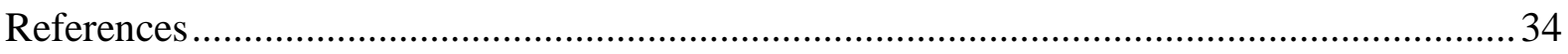

\section{Nomenclature}

$B i$ : Biot number

$K_{p}$ : Half-saturation constant for short-term Fe uptake (M)

$N_{b}$ : Bulk nitrogen concentration $(\mathrm{mg} / \mathrm{l})$

$N_{g}$ : Nitrogen concentration within the gel bead $(\mathrm{mg} / \mathrm{l})$

$N_{s}:$ Interfacial nitrogen concentration $(\mathrm{mg} / \mathrm{l})$

$r$ : Radial coordinate $(\mathrm{cm})$

$t$ : Cultivation time (days) (Equation (2)); Time coordinate (s) (Equations (3) and (4))

$X$ : Algal biomass concentration $(\mathrm{g} / \mathrm{L})$

$X$ : Variable; $X_{1}=\mathrm{NaNO}_{3}(\mathrm{~g} / \mathrm{L}) ; X_{2}=\mathrm{CaCl}_{2}(\mathrm{~g} / \mathrm{L}) ; X_{3}=$ Citric acid stock $(\mathrm{ml} / \mathrm{L}) ; X_{4}=$ Trace metal mix (ml/L)

$X_{0}$ : Initial algal biomass concentration $(\mathrm{g} / \mathrm{L})$

$X_{m}$ : Maximum biomass in logistic equation in unit of $(\mathrm{g} / \mathrm{L})$

$Y$ : Phycocyanin production $(\mathrm{mg} / \mathrm{ml})$ 
$\alpha$ : Ratio of total volume of beads available for liquid mass transfer to volume of medium solution

$\beta_{o}, \beta_{i}, \beta_{i i}, \beta_{i j}$ : Constant process effect in the total, the linear, the quadratic effect of $X_{i}$, and the interaction effect between $X_{i}$ and $X_{j}$

$\mu$ : Initial specific growth rate in unit of (1/day)

$\rho:$ Uptake rate $(\mathrm{mol} / \mathrm{cell} / \mathrm{s})$

$\phi^{2}$ : Thiele modulus

\section{Introduction}

In recent times the microalgal production industry has capitalized on advances in biotechnology to expand and diversify. ${ }^{1-8}$ It now exploits a wider range of species amenable to mass culturing, and their corresponding applications, which go beyond biofuels. For instance, mass cultured microalgae has been valorized as health food products. ${ }^{9,10}$ This shift has sparked interest in the development of economical techniques to extract high-value chemical compounds from microalgae. One such class of valuable compound are photosynthetic pigments. ${ }^{11-17}$ This article provides insights into the knowledge and the strategies involved with phyco-valorization, the exploitation of microalgae and microalgal chemicals as valuable products, by taking the pigment phycocyanin as an exemplar.

Phycocyanin is a light-harvesting pigment and nitrogen-storing protein found in the prokaryotic cyanobacteria species, as well as in eukaryotic chlorophyta, rhodophyta, and bacillariophyta species. ${ }^{18}$ Phycocyanin is a type of chromoprotein (or biliprotein) that absorbs radiation in regions of the visible spectrum where chlorophyll $a$ has low absorptivities. ${ }^{19}$ According to the naming convention of $\mathrm{MacColl}^{19}$, four varieties of phycocyanin have been identified, each having a different type or combination of phycobilin (light-capturing pigments, shown in brackets): C-phycocyanin (phycocyanobilin); phycoerythrocyanin or CV- 
phycocyanin (phycocyanobilin, phycoviolobilin); R-phycocyanin II or CE-phycocyanin (phycocyanobilin, phycoerythrobilin); phycocyanin WH8501 or CU-phycocyanin (phycocyanobilin, phycourobilin). C-phycocyanin has been identified as a promising candidate for phyco-valorization due to its array of functionalities, which enable many different applications. ${ }^{20,21}$ All further references to phycocyanin in this paper relate to Cphycocyanin.

A primary consideration for a potential phycocyanin producer is the selection of a microalgal species amenable to the conditions of the prospective production system. An individual species will demonstrate optimal growth within a specific range of process parameters. Throughout this article, the optimization of such parameters will be analyzed demonstrating the dynamic range of optimal conditions reported for a number of microalgae species.

Another important consideration is the cost of the microalgal cultivation and harvesting process. Based on sustainability precepts, a potential route to reducing costs is by utilization of waste resources or unused infrastructure. Potential resources that can be drawn include substrate sources, $\mathrm{pH}$ adjusting materials, heat sinks, and available light.

Phycoremediation is a microalgal technology that has had promising amenability to resource recovery from a variety of waste streams. ${ }^{22-31}$ An integrated resource recovery concept may also be beneficial to microalgal phycocyanin producing systems, and will be discussed in this paper.

\section{Applications of Phycocyanin}

A critical aspect of phycocyanin that has contributed to its rising popularity for commercial production is its inherent nutraceutical function. One microalga championing the health benefits of phycocyanin is Arthrospira platensis (formerly known as Spirulina 
platensi $^{32}$ ). This species of cyanobacteria has recently drawn great interest from the health food industry and academia; the integration of $A$. platensis into a wide variety of food products, taking advantage of phycocyanin's nutraceutical attributes, has been explored..$^{20,21}$ Table 1 summarizes literature identifying various nutraceutical functions of phycocyanin. The intense cyan coloration of phycocyanin has led to its use as a colorant for food and cosmetic applications. It is of particular importance to these industries in view of increased consumer preference for natural colorants in place of their potentially toxic synthetic counterparts. ${ }^{57}$ Health conscious consumers also benefit from the imparted nutraceutical properties. This trend corresponds with the increased popularity of phycocyanin colorant following its introduction in Japan by Dainippon Ink \& Chemicals Incorporated in $1980 .{ }^{34}$ This is further exemplified by the recent ruling from the U.S. Food and Drug Administration that allowed the usage of phycocyanin derived from Spirulina (former nomenclature) to be exempt from colorant certification. ${ }^{58}$

Related to the characteristic blue coloration of phycocyanin are the innate fluorescent properties of the chemical. In particular, phycocyanin has been found to absorb light at $620 \mathrm{~nm}$ while emitting light at $640 \mathrm{~nm} .{ }^{35,59}$ This property has been found to have far reaching significance in several fluorescence-based applications, which are summarized in Table 1. A comprehensive review of the supporting properties of the phycocyanin molecule contributing to the current interest in fluorescent applications has been compiled by Glazer. ${ }^{52}$

Phycocyanin sensing is a potential detection method for measuring growth of cyanobacteria cultures and detecting cyanobacteria population in drinking water or native environs. ${ }^{42,60}$ This aspect of phycocyanin has become increasingly important for water quality initiatives, as cyanobacterial blooms have been associated with toxic metabolite accumulation as well as drinking water sensory quality degradation. Through the collection of fluorescent 
light absorbance data corresponding with phycocyanin concentrations, cyanobacterial blooms may be detected before populations have grown to dangerous or detrimental levels. ${ }^{61,62}$

The applications that have reached commercial scale include nutraceuticals, food and cosmetic colorants, and fluorescent probes for cellular and molecular detection. ${ }^{60}$ The overall phycocyanin market value has been estimated at U.S. \$ 10-50 million annually, with the price of phycocyanin ranging between U.S. \$ 130-5,000 per kg depending on the grade. ${ }^{63-65}$ With the cost of dry algal biomass alone estimated at U.S. \$ 15-25 per kg, the significance of optimizing systems for increased phycocyanin productivity is crucial in maximizing the economic efficiency of algal production systems. Further expansion of the current phycocyanin markets may be possible as the bioeconomy expands and new opportunities for exploitation of its nutraceutical, colorant and fluorescent functionalities are found.

\section{Phycocyanin Production Parameters}

Current research on the microalgal production of phycocyanin has focussed on the establishment of optimal culture conditions. In the development of phycocyanin production systems for commercialization, such research may be used as benchmark for scale-up. Crucial parameters for phycocyanin production and their optimization strategies are reviewed in this section. Table 2 summarizes the system conditions where optimal phycocyanin productivity is achieved and the maximal transient productivities obtained (which ranged from 0.005 to $\left.0.86 \mathrm{~g} \cdot \mathrm{L}^{-1} \cdot \mathrm{d}^{-1}\right)$.

\section{Trophicity and Symbiosis}

The trophic mode of the system is of particular significance in establishing a phycocyanin production system. Trophicity stands for the relationship of different organisms in an ecological community with the food resources in that system. Photoautotrophic 
cultivation with A. platensis currently dominates the phycocyanin production market. ${ }^{78}$ This is a product of the ease of biomass production rather than an optimization of phycocyanin productivity. A. platensis is generally cultivated axenically in common open-pond systems under natural sunlight and is a preferred species due to its proliferation in extreme $\mathrm{pH}$ of up to $10.5{ }^{79}$ This characteristic is important as $\mathrm{CO}_{2}$ absorption from the atmosphere is promoted at higher $\mathrm{pH}$, which also helps maintain a monoalgal culture. This alone, however, does not constitute optimization of phycocyanin productivity. Rather, for particular species, mixotrophic production that combines the sum of photoautrophic and heterotrophic productivities can offer an increase in overall system's phycocyanin productivity, albeit with increased system complexity. For instance, a mixotrophic system is dually limited, in that it is simultaneously limited by either low or high light intensity (which affects the photoautotrophs) and by either low or high concentration of organic carbon substrate (which affects the chemoheterotrophs). ${ }^{80}$ Consequently, stricter process control measures are required to maintain optimal productivity.

Previous research analyzing solely heterotrophic cyanobacteria cultivation had shown subpar results. Marquez et al. noticed significantly reduced concentrations of the pigments chlorophyll-a $(-48 \%)$, carotenoids $(-56 \%)$ and phycocyanin $(-53 \%)$ under heterotrophic conditions compared to autotrophic conditions. ${ }^{81}$ Trabelsi et al. studied the production of biopolymer (in the form of extracellular polymeric substances (EPS)) from A. platensis and found the highest specific productivity $\left(433.62 \mathrm{mg} \cdot \mathrm{g}^{-1} \cdot \mathrm{d}^{-1}\right)$ under photoautotrophic culture, while heterotrophic culture yielded the lowest specific EPS productivity $\left(38.33 \mathrm{mg} \cdot \mathrm{g}^{-1} \cdot \mathrm{d}^{-1}\right) \cdot{ }^{82}$ This result was attributed to the conversion of organic substrate into biomass rather than EPS under dark conditions.

Yet, recent studies with the rhodophyta species Galdieria sulphuraria have sparked renewed interests in heterotrophic production. An important development made was 
overcoming relatively low specific phycocyanic concentration in the cells $\left(3-4 \mathrm{~g} \cdot \mathrm{kg}^{-1}\right.$ (dry weight, DW) for G. sulphuraria $074 G$ versus $60-74 \mathrm{~g} \cdot \mathrm{kg}^{-1}$ (DW) for A. platensis) by means of high rates of biomass production that heterotrophic species provide. ${ }^{74}$ Particularly, Graverholt and Eriksen were able to achieve the highest recorded phycocyanin productivity of $860 \mathrm{mg} / \mathrm{L} /$ day culturing $G$. sulphuraria heterotrophically. ${ }^{74}$ To achieve this, a high rate of biomass production at high biomass concentration $\left(83.3 \mathrm{~g} \cdot \mathrm{L}^{-1}(\mathrm{DW})\right)$ was used in continuousflow culture mode, together with a strain having relatively high specific phycocyanin concentration $\left(15.6 \mathrm{mg} \cdot \mathrm{g}^{-1}\right.$ (biomass DW).

The development of a microalgal polyculture system has also been suggested. ${ }^{83} \mathrm{Such}$ systems would take advantage of the diverse range of optimal growth conditions and metabolic mechanisms found among microalgal species by selecting species known to produce high-value metabolites such as phycocyanin. An economically sound system may be achieved as such strategy effectively increases the system's capacity for phycocyanin generation. This approach to microalgal cultivation has been slow to disseminate in the research community because there is such a wide variety of metabolisms developed by microalgae as observed in nature, so the use of a cultivation method based on mixed species with different specific metabolic capabilities requires extensive investigation to explore all possible combinations of species. ${ }^{83}$ The benefits are evident, however, since the polyculture of mixed microalgal species, combining species with different metabolic abilities (e.g. the use of different forms of $\mathrm{N}, \mathrm{C}$ and contaminants) may improve the overall production or phycoremediation capacity of cultures when supplemented with multiple or varying nutrient resources. ${ }^{83}$

Costa et al. examined the simultaneous cultivation of A. platensis and Microcystis aeruginosa ${ }^{84}$ It was found that the highly toxigenic $M$. aeruginosa did not have an effect on the growth of A. platensis. This could lead to reduced water supply costs for a microalgal 
bioreactor; the cited study proposed using lagoon water as the main portion ( $80 \mathrm{vol} \%)$ of the culture medium. Currently, bioreactor water supplies are monitored and filtered to remove toxic bacteria. By eliminating this process and encouraging the symbiotic growth of the microalgae, this cost can be reduced or eliminated. Symbiosis stands for the close relationship between two species living in an ecological community. Another possible benefit of such system comes from the toxic metabolite production of $M$. aeruginosa. These compounds act as barriers to other organisms and prevent system contamination; this constitutes a commensalistic symbiosis (where one member of the community benefits while the other is not affected). Recent research has demonstrated that cyanobacterial toxins can function as algaecides, herbicides, larvicides and fungicides. ${ }^{85}$ This has an added value to symbiotic phycocyanin production: the toxins generated can be removed as additional products, providing an opportunity for further economic benefit of the overall manufacturing process. Caution must be exercised, however, since cross-contamination of food-grade phycocyanin with toxic metabolites would pose a safety risk to the consumer. In these cases, highly effective harvesting processes are required to ensure complete separation, or perhaps preferably, co-culturing toxigenic microalgae should be limited to the production of phycocyanin for industrial applications.

\section{Lighting Conditions}

The optimization of photoautotrophic microalgae growth and metabolite production is significantly affected by lighting conditions, as the organisms utilize energy from light sources to drive metabolic activity. The light-harvesting pigment phycocyanin is directly linked to the photosynthetic processes of microalgae. Discussed within this section are numerous studies that have examined and confirmed the critical effect of lighting parameters 
on phycocyanin production. Thus, comprehension of lighting condition relations can be applied to the improvement of overall system phycocyanin productivity.

\section{$\underline{\text { Light Intensity }}$}

Research has shown that light intensity has a significant effect on microalgal phycocyanin production. Chen et al. determined that phycocyanin productivities in the cyanobacteria Arthrospira platensis increased to a maximum at $700 \mu \mathrm{mol} / \mathrm{m}^{2} / \mathrm{s}$ photon flux density, due to an observed light intensity inhibition of cell growth above this level. ${ }^{66}$ Takano et al. analyzed the effect of varying light source intensity on phycocyanin productivity of Synechococcus sp. NKBG 042902, and measured a maximum productivity at a photon flux density of $55 \mu \mathrm{mol} / \mathrm{m}^{2} / \mathrm{s}$ at the surface of the culture vessel. ${ }^{77}$ It is notable from Table 2 that the optimal light intensity even for a single species varies widely: optimal values for $A$. platensis vary from as low as $15 \mu \mathrm{mol} / \mathrm{m}^{2} / \mathrm{s}$ to as high as $3000 \mu \mathrm{mol} / \mathrm{m}^{2} / \mathrm{s}$. It is unclear from the experimental methodologies why these values are so different; most works report the use of LI-COR quantum sensors, so measurement method does not appear to be the culprit. What is notable from Table 2 is that studies that report a higher optimal light intensity also report, generally, higher maximal transient phycocyanin productivities; so at least the two parameters appear to be linked: higher intensity results in higher productivity. It may signify that those studies that achieve higher productivities have better optimized other culture parameters and photobioreactor design.

\section{Light Source Emission Spectra}

Each photosynthetic pigment is adapted to absorb light within a specific range. ${ }^{86}$ The spectral absorbance and fluorescence emittance wavelength maxima of phycocyanin have been determined as $620 \mathrm{~nm}$ and $640 \mathrm{~nm}$, respectively. ${ }^{35,59}$ It has been found that manipulation of light source emission spectra significant impacts both phycocyanin purity and productivity. Walter et al. found that applying a red-colored light filter to a A. platensis photobioreactor 
system resulted in the highest phycocyanin purity as well as productivity per unit light intensity when compared to unfiltered, blue-filtered, and yellow-filtered light. ${ }^{67}$ Similar results were achieved by Rodriguez et al. ${ }^{87}$ A study on the effect of light quality on Synechococcus $s p$. NKBG 042902 phycocyanin production determined that a range of 620$725 \mathrm{~nm}$ light source resulted in the greatest phycocyanin productivity when compared to broad spectrum light sources of emission wavelength maxima of 450-575 $\mathrm{nm}$ and 450-650 nm. ${ }^{77}$ The maximal phycocyanin productivity determined by these experiments predominantly corresponds with absorption spectrum of phycocyanin.

\section{Climatic and Nutritional Conditions}

When optimizing microalgal phycocyanin production, attributes of the local climate must be taken into consideration. The local temperature and water source $\mathrm{pH}$ have been found to pose significant effect on microalgal phycocyanin production. Moreover, productivity is significantly affected by the nutritional contents of the growth media.

\section{Temperature}

The optimal temperature range for phycocyanin production is highly dependent on the microalgal species, due to the extensive variation of native climate. Numerous studies on the relation of temperature to phycocyanin productivity and purity for species native to warm climates have been conducted. ${ }^{75,81,88,89}$ For A. platensis, Arthronema africanum, and Anabaena albufera, the optimal temperature for phycocyanin productivity has been determined to be $35{ }^{\circ} \mathrm{C} .{ }^{87-89}$ Kenekar and Deodhar found that phycocyanin concentration of Geitlerinema sulphureum peaked at $25^{\circ} \mathrm{C}$ and started decreasing above that, despite increasing biomass productivity. ${ }^{75}$ Although these temperatures correspond with temperate climates exclusive to specific geographies, phycocyanin producing microalgae are known to proliferate in both extreme heat and cold. The thermophilic cyanobacteria Synechococcus 
lividus produces thermally-stable phycocyanin (which preserved light absorption functionality at $70^{\circ} \mathrm{C}$ and became only slightly hypochromic at $80{ }^{\circ} \mathrm{C}$ ) while maintaining growth at temperatures of up to $73{ }^{\circ} \mathrm{C} .{ }^{90}$ Conversely, arctic acclimated cyanobacteria (Scytonema spp. and Phormidium spp., among other subdominant species) have had phycocyanin production identified. ${ }^{91}$ Table 2 summarizes the temperatures used for optimal phycocyanin productivity. Notably, the study that reported the highest transient phycocyanin productivity $\left(0.86 \mathrm{~g} \cdot \mathrm{L}^{-1} \cdot \mathrm{d}^{-1}\right)$ also utilized the highest temperature of the set $\left(42{ }^{\circ} \mathrm{C}\right)$, but for the several studies that used $30{ }^{\circ} \mathrm{C}$, the productivity values varied widely: $0.005-0.13 \mathrm{~g} \cdot \mathrm{L}^{-}$ $\left.{ }^{1} \cdot \mathrm{d}^{-1}\right)$. Therefore, higher temperature does not correlate conclusively with high productivity. Also, it should be noted that optimal temperature alone does not ensure optimal productivity, but rather multi-parameter optimization is required.

$\underline{p H}$

The $\mathrm{pH}$ of culture media is a critical factor in maintaining optimal algal metabolism. Research has shown that variations in media $\mathrm{pH}$ may have an effect on phycocyanin productivity. Ogbonda et al. studied the influence of $\mathrm{pH}$ variation on Arthrospira sp. growth and composition, concluding that maximized protein productivity was achieved at $\mathrm{pH} 9.0$, noting that the solubility of $\mathrm{CO}_{2}$ and other mineral compounds is affected by $\mathrm{pH}$; however no explanation was given for the subsequent decline in productivity at even higher $\mathrm{pH} .{ }^{92}$ It can be noted from their results, however, that higher productivity of crude protein correlated well with lower productivity of carbohydrate and crude fiber. Similarly, Morales et al. determined an optimal $\mathrm{pH}$ of $8.0-9.0$ for phycocyanin productivity for a semicontinuous culture of Anabaena sp. PCC $7120 .{ }^{73}$ According to Markou et al., an excessive rise of the medium $\mathrm{pH}$ can affect negatively the growth of microalgae either by the alkaline environment itself or due to low useful carbon availability, as carbonate $\left(\mathrm{CO}_{2}^{-3}\right)$ gradually becomes the dominant dissolved inorganic carbon form available (as opposed to bicarbonate at $\mathrm{pH} \sim 6.5-10.5$ ) and 
only some extremely alkaliphilic cyanobacteria can utilize carbonate. ${ }^{93}$ It should also be noted that the cyanobacterial amenability to extreme temperatures can be analogously extended to viable $\mathrm{pH}$ ranges. For example, G. sulphuraria and A. platensis are two promising cyanobacteria species for phycocyanin production known to grow in media at $\mathrm{pH} 2$ and 9 , respectively. ${ }^{66,74}$ This could be exploited in phycocyanin production systems to enable microalgal proliferation using a local water source with minimal $\mathrm{pH}$ adjustment.

\section{$\underline{\text { Media }}$}

The production of phycocyanin in microalgal bioreactor systems occurs through a process of biosynthesis of metabolites in substrate media. The abundance of phycocyaninproducing cyanobacterial species coincides with a diverse variation of native substrates. Nonetheless, the significance of the media's composition is uniform regardless of species. Control of nitrate, phosphate, dissolved $\mathrm{CO}_{2}$, and overall salt concentrations in substrate media have been demonstrated as essential for the optimization of phycocyanin production. 76,94

While acting as a pigment-protein for the photosynthetic antennae of cyanobacteria (phycobilisomes), phycocyanin also functions as a nitrogen-storing component. According to Jin et al., nitrate $\left(\mathrm{NO}_{3}{ }^{-}\right)$is consumed more quickly than the other medium constituents, and thus becomes a limiting factor at an early stage of cultivation..$^{94}$ This has also been observed with algal blooms in nature, where nitrate becomes the primary limiting nutrient for algal proliferation in surface water. ${ }^{94}$

Research has found that the substrate nitrate concentration and source are key factors in regulating phycocyanin productivity. Chen et al. found that maximum phycocyanin productivity for $A$. platensis is achieved with $\mathrm{NaNO}_{3}$ concentration of $0.045 \mathrm{M} .{ }^{66}$ Also, the degradation of phycocyanin is associated with the depletion of substrate nitrate, as phycocyanin is utilized as a secondary nitrogen source in the absence of nitrate. Similar 
findings were reported by Szalontai and Csatorday for the cyanobacteria Anacystis nidulans. ${ }^{95}$ Kenekar and Deodhar determined that phycocyanin productivity of $G$. sulphureum increased by four times when increasing $\mathrm{NaNO}_{3}$ concentrations from 1.5 up to $4.5 \mathrm{~g} / \mathrm{L} .^{75}$ These findings concur with the observed functionality of phycocyanin as a nitrogen storage compound in microalgae. ${ }^{66}$

A further attribute affecting phycocyanin productivity of cyanobacteria is the type of chemical used as the nitrogen source. Research has shown that the use of ammonium $\left(\mathrm{NH}_{4}^{+}\right)$ rather than nitrate as the nitrogen source for the growth of Agmenellum quadruplicatum PR-6 and Calothrix sp. strain PCC 7601 resulted in higher phycocyanin concentrations. ${ }^{96,97}$ This effect was correlated by De Lorimier et al. to a higher cpcBA/apcAB RNA ratio detected in ammonium-grown cultures compared to nitrate-grown cultures, at a given irradiance. ${ }^{97}$ Liotenberg et al. postulated that the changes in biliprotein content (phycocyanin versus phycoerythrin) are a means of adjusting the photosynthetic activity, in such a way that the production of reducing power does not exceed its demand. ${ }^{96}$ Because ammonium-N is assimilated directly, whereas nitrate- $\mathrm{N}$ must be reduced (from +5 to -3 oxidation state),${ }^{97}$ the reducing power demand in lower in the case of ammonium-grown cells.

Markou et al. developed a unique approach for supply of ammonia $\left(\mathrm{NH}_{3}\right)$ from wastewater, whereby a natural zeolite (clinoptilolite type) was used as medium for the sorption of ammonia from wastewater and subsequently as nitrogen releaser in cultures of $A$. platensis. ${ }^{98}$ According to Liotenberg et al., when externally supplied, ammonium ions enter the cells via an active transport system, while the unprotonated form (ammonia) enters by diffusion and is trapped by protonation. ${ }^{96}$ The dependence of phycocyanin productivity on media nitrogen availability is a critical consideration in overall system design, and in some cases intermittent nitrogen feeding methods (e.g. fedbatch mode) ${ }^{94}$ may have to be used to sustain productivity. 
Phosphorous is another important nutrient for microalgal growth, present as a component of several organic molecules such as nucleic acids (RNA and DNA), membrane phospholipids and ATP, and thus making up $0.05-3.3 \%$ of biomass. ${ }^{93}$ Phosphorus is frequently a limiting nutrient for microalgae, especially in natural environments, and can be found in various forms such as orthophosphate, polyphosphate, pyrophosphate, metaphosphate and their organic forms. ${ }^{93}$ Depraetere et al. studied the effect of phosphate concentration of the growth of A. platensis. ${ }^{99}$ That study was particularly concerned not to remove phosphate when treating piggery wastewater for color removal, as that would adversely affect the subsequent microalgal cultivation. Chitosan application resulted in $>90 \%$ color removal with $<20 \%$ phosphate $\left(\mathrm{PO}_{3}{ }^{4-}\right)$ removal. Upon culturing in media with initial $\mathrm{PO}_{4}-\mathrm{P}$ concentration of $\sim 12-13 \mathrm{mg} \cdot \mathrm{L}^{-1}$, biomass yield of $A$. platensis was nearly $50 \%$ higher in the chitosan decolored treatment than in the control treatment that was not decolored. Markou et al. used P-loaded zeolites (at $10.3 \mathrm{mg}-\mathrm{P}$ per g of zeolite) that supplied $\mathrm{PO}_{4}-\mathrm{P}$ concentrations of $1.55-51.5 \mathrm{mg} \cdot \mathrm{L}^{-1}$ to cultures of Chlorella vulgaris and A. platensis, with adequate growth being achieved for both species at the highest concentration. ${ }^{100}$

Carbon dioxide $\left(\mathrm{CO}_{2}\right)$ is an integral part of metabolic processes in photoautotrophic cyanobacteria. This concept has led to studies to determine the relation of $\mathrm{CO}_{2}$ and phycocyanin productivity. Morales et al. concluded that the addition of $0.03 \% \mathrm{CO}_{2}$ (i.e. air) in a semi-continuous culture of Anabaena sp. PCC 7120 resulted in significantly greater phycocyanin concentrations than $5 \% \mathrm{CO}_{2}$ addition. ${ }^{73}$ The $\mathrm{pH}$ of the medium remained relatively low in the latter case $(7.4-7.8)$ compared to the former (which increased over time from 7.8 to 10). Similar results were achieved by Zeng et al., where it was determined that intermittent $20 \mathrm{mM} \cdot \mathrm{L}^{-1} \cdot \mathrm{d}^{-1}$ of $\mathrm{CO}_{2}$ diluted in continuous $0.1 \mathrm{~L} \cdot \mathrm{min}^{-1}$ of air corresponded with the highest phycocyanin productivity in a A. platensis culture. ${ }^{68}$ In this case, the added $\mathrm{CO}_{2}$ attenuated the $\mathrm{pH}$, due to its acidification effect, preventing it from surpassing 10 and 
stabilizing it around 9. The reported phycocyanin productivity was lower (by 16-26\%) when the culture was supplemented with the same flow rate of $\mathrm{CO}_{2}$ or air alone. These results demonstrate that the moderation of $\mathrm{CO}_{2}$ addition to bioreactor phycocyanin production systems is essential for optimization.

Further research has been conducted to analyze the effects of sodium bicarbonate and sodium carbonate additions to culture media on cyanobacteria phycocyanin productivity. Kenekar and Deodhar determined that phycocyanin productivity of G. sulphureum increased with increasing sodium bicarbonate concentration (between 0 and $10 \mathrm{~g} / \mathrm{L}$ ). ${ }^{75}$ Bicarbonate acts as a $\mathrm{pH}$ buffer. Also, it was determined that a sodium carbonate concentration of $6.24 \mathrm{~g} / \mathrm{L}$ resulted in the maximum phycocyanin productivity, 2.6 times higher than in the presence of $10 \mathrm{~g} / \mathrm{L}$ bicarbonate alone.

A statistical analysis on media composition optimization for increased phycocyanin production from Phormidium ceylanicum was accomplished by Singh et al. ${ }^{76}$ The concentrations of the four major components of BG-11 medium, namely $\mathrm{NaNO}_{3}$, $\mathrm{CaCl}_{2} \cdot 2 \mathrm{H}_{2} \mathrm{O}$, citric acid stock and trace metal mix, were optimized, at fixed concentrations of $\mathrm{K}_{2} \mathrm{HPO}_{4}$ and $\mathrm{MgSO}_{4} \cdot 7 \mathrm{H}_{2} \mathrm{O}$. It was determined that citric acid addition had a beneficial effect on phycocyanin productivity concurrently with increasing nitrate concentration. An approximate optimal ratio of citric acid stock (composition per $100 \mathrm{ml}: 0.06 \mathrm{~g}$ citric acid, $1 \mathrm{mg}$ EDTA, $0.06 \mathrm{~g}$ ferric ammonium citrate, $0.4 \mathrm{~g}$ anhydrous sodium carbonate) to sodium nitrate concentration was found to be $30 \mathrm{ml} / \mathrm{L}: 4 \mathrm{~g} / \mathrm{L}$. Also, the optimization of trace metal concentration to nitrate ratio was determined to be approximately $0.9 \mathrm{ml} / \mathrm{L}$ of trace metal mixture (composition per $100 \mathrm{ml}: 0.286 \mathrm{~g} \mathrm{H}_{3} \mathrm{BO}_{3}, 0.181 \mathrm{~g} \mathrm{MnCl}_{2} \cdot 2 \mathrm{H}_{2} \mathrm{O}, 0.022 \mathrm{~g}$ $\left.\mathrm{ZnSO}_{4} \cdot 7 \mathrm{H}_{2} \mathrm{O}, 0.039 \mathrm{~g} \mathrm{Na}_{2} \mathrm{MoO}_{4} \cdot 2 \mathrm{H}_{2} \mathrm{O}, 0.005 \mathrm{~g} \mathrm{Co}\left(\mathrm{NO}_{3}\right) \cdot 6 \mathrm{H}_{2} \mathrm{O}, 0.008 \mathrm{~g} \mathrm{CuSO}_{4} \cdot 5 \mathrm{H}_{2} \mathrm{O}\right)$ to $4 \mathrm{~g} / \mathrm{L}$ sodium nitrate. Overall, this study concluded that through an application of statistical media composition optimization, a phycocyanin productivity increase of 2.3 -fold was 
achieved compared to the original BG 11 medium, which was originally developed for isolation of freshwater blue-green algae. ${ }^{101}$

\section{Operating System}

Current methods of production for phycocyanin-containing microalgae include openpond and closed bioreactor systems. Open-pond systems constitute the traditional method of microalgae production as well as the most common method of industrial microalgae production today. ${ }^{102}$ This may be seen as a result of their relatively low investment cost and simplicity of design. Due to the open and uncontrolled nature of open-pond systems, however, their design is not amenable to optimization of phycocyanin productivity. Rather, the local environment of the pond strongly determines the phycocyanin productivity. A particular issue stemming from the open nature of these systems is the elevated risk of microbial contamination. This can have negative impacts on various aspects of the phycocyanin production, such as a reduction in available media, decreased phycocyanin purity, introduction of unfavourable symbiotic relationships, or introduction of toxic compounds that require further processing for removal. Other limitations of open-pond systems include: poor light utilization, inefficient temperature control, and susceptibility to substrate concentration variation due to evaporative losses, $\mathrm{CO}_{2}$ desorption and inefficient media mixing. ${ }^{103}$ Current research has shown maximum phycocyanin productivity levels for open-pond systems to range between $3-24 \mathrm{mg} \cdot \mathrm{L}^{-1} \cdot \mathrm{d}^{-1} \cdot{ }^{104-106}$

Contrary to open-pond systems, closed bioreactor systems are intricately controlled to maintain optimal growth conditions. Research has shown that commonly controlled parameters of the closed-bioreactor systems also have an effect on phycocyanin productivity. The adoption of closed bioreactor systems has resulted in improved phycocyanin productivities, reported at levels ranging between $64-860 \mathrm{mg} \cdot \mathrm{L}^{-1} \cdot \mathrm{d}^{-1} \cdot{ }^{18,66}$ The potential of 
several types of closed microalgal bioreactor systems has been analyzed at pilot-scale. Bioreactor designs of particular interest include flat-plate and tubular type systems. Both systems provide improvements over the traditional open-pond system through enhanced light source efficiency by increased surface area to volume ratio, elevated $\mathrm{CO}_{2}$ retention, and reduced contamination risk. Ultimately, these benefits have been proven to allow for far greater culture population densities and phycocyanin productivity. ${ }^{66,103,107}$

Table 3 summarizes reported bioreactor operational parameters whereat maximal phycocyanin productivity was achieved. A primary element in the design of bioreactor systems is the operational mode. A comparison may be drawn from recent research utilizing varied batch, fed-batch and continuously operated microalgae production systems. Batch mode has been the most common configuration used in the research domain, followed by fedbatch. Batch systems are the least amenable to increasing phycocyanin productivity due to a lack of reactor content concentration control. The nature of batch systems of adding all media components at the beginning of culture growth is the source of the issue. This attribute of batch systems has been demonstrated to produce detrimental effects on phycocyanin productivity. $^{70}$

Fed-batch systems eliminate the issues present in batch systems by stepwise additions of substrate, inoculum and other contents into the bioreactor. This method of addition corresponds with increased steadiness of optimal production conditions. ${ }^{108}$ Literature has demonstrated the beneficial attributes of fed-batch systems in increased phycocyanin production in microalgal systems. Chen and Zhang found that overall phycocyanin content increased by 2.8 -fold when comparing fed-batch and batch $A$. platensis bioreactors cultures. ${ }^{70}$ Other research with A. platensis production has found that fed-batch systems allow for a 2.7fold increase in biomass when compared to batch systems. ${ }^{109}$ Although a fed-batch operating bioreactor offers increased constituent concentration control, a lack of control transpires 
throughout downtime between additions. Continuous systems are an alternative operational mode for bioreactors that minimize this issue, although these require more research for use in microalgal phycocyanin production.

The highest phycocyanin productivity reported in recent research (Table 3) was achieved by culturing Galdieria sulphuraria in a continuous bioreactor. ${ }^{74}$ This was possible because the continuous-flow culture enabled constantly high biomass concentration and the relatively high specific growth rate. Other research has demonstrated many cyanobacterial species with favourable amenability to continuous bioreactor production including $A$. platensis, Phormidium bigranulatum and Microcystis spp. ${ }^{110-114}$ Continuous systems are characterized by constant monitoring and adjusting of reactor contents. Although this may maximize phycocyanin productivity, the resource investment for such a system would be substantial due to a lack of current technology. In the design of a microalgal phycocyanin production system, thorough analysis is required to determine optimal operational mode for both productivity and economics. In addition to bioreactor optimization, consideration must also be given to other steps in the production systems, such as separation, drying, extraction, etc.

Experimental reactor volumes have ranged in size from $250 \mathrm{ml}$ to 50 litres, with mixing rates varying from stationary to $500 \mathrm{rpm}$ (Table 3). Mixing was achieved either by gas sparging alone, rotary shakers or with the use of impellers; gas sparging, together with suitable reactor geometry, is favourable for lower operating cost. Forced aeration in photobioreactors was mainly done with sterile air, while experiments performed in flasks typically did not use forced aeration. Maximal phycocyanin productivity was achieved in batch systems after several days, while the continuous reactor was able to sustain high productivity with a residence time of 1.8 days $(=2.5 \mathrm{~L} /(1.38 \mathrm{~L} /$ day $))$. 
An issue introduced by the closed nature of photobioreactors is the increased $\mathrm{O}_{2}$ retention as a product of photosynthesis. Many algal species cannot tolerate oxygen levels above normative air saturation. Furthermore, increasing $\mathrm{O}_{2}$ concentrations have been found to decrease photosynthetic efficiencies of A. platensis, which may result in decreased phycocyanin productivity. ${ }^{107}$ To alleviate this, specific mixing regimes have been suggested. These mixing systems aim to provide adequate $\mathrm{O}_{2}$ removal and culture distribution while limiting shear stress that may potentially damage the microalgae cells. Tredici and Materassi proposed the use of vertical alveolar panels, where mixing and deoxygenation of the culture suspension are effected by continuously bubbling air in the bottom of the panel. ${ }^{115}$ They also noted that in serpentine design photobioreactors, the maintenance of oxygen concentrations compatible with growth of the selected algal species requires the installation of too many degassing stations, making the design impractical and non-economical. Comparatively, closed photobioreactors have so far seen little adoption in the industrial production of microalgae and phycocyanin due to the long road for technological development and the accompanying large capital costs.

\section{Phycocyanin Production Modelling}

To further the comprehension of microalgal phycocyanin production mechanism, predictive growth models have been proposed in literature. Currently identified models have commonly correlated variables of substrate nutrient concentrations, light intensity, biomass concentration, and particular product concentrations. Chojnacka and Noworyta have documented a summary of models for the growth of photoautotrophic microorganisms from

literature. ${ }^{116}$ A further resource by Yuan et al. provides a consolidation of microalgae models investigating the effect of additional system parameters. ${ }^{117}$ Such models may be applied to photobioreactor cultivation of microalgae to determine system conditions required for 
optimal phycocyanin productivity. The benefits of microalgal population growth models include: (i) the establishment and maintenance of proper system cellular population density; (ii) the determination of optimal system parameters through an economically sound approach; (iii) aiding the upscaling of bench top systems to larger commercial manufacturing facilities. Table S1 in the Supporting Information summarizes established literature models of microalgal phycocyanin production. Most models are mechanistic in nature and take the Haldane equation into account to simulate substrate inhibition effects. The one notable exception is the model proposed by Singh et al. (Equation (1)), which is based on Response Surface Methodology. ${ }^{76}$ It is a statistical modelling technique whose objective is to determine the optimal operational condition for the system or to determine a region that satisfies operating specifications. An experimental program utilizing central composite design in needed to calibrate the model. The authors were able to increase phycocyanin productivity from $P$. ceylanicum by 2.3 -fold by finding the optimal medium composition, and found good agreement between predicted and experimental values $\left(R^{2}=94.00\right.$, signal to noise ratio $=$ 17.964).

$$
Y=\beta_{0}+\sum \beta_{i} X_{i}+\sum \beta_{i i} X_{i}^{2}+\sum \beta_{i j} X_{i} X_{j} \cdots
$$

Tables S2a and S2b in the Supporting Information summarize established literature models of cyanobacteria biomass production. Main differences between the models include taking light intensity into account for photoautotrophic species, and considering either carbon or nitrogen as the limiting substrate. Chen et al. investigated the effect of LED color on growth kinetics, but their model equation (Equation (2)) does not have a term for light wavelength or intensity; rather, color and intensity are taken into account through the datafitted constants $\mu$ (maximum biomass concentration) and $X_{m}$ (initial specific growth rate). ${ }^{71}$ 
Red light gave the best performance, and blue the poorest; values of $\mu$ and $X_{m}$ at the highest intensity $\left(3000 \mu \mathrm{mol} \cdot \mathrm{m}^{-2} \cdot \mathrm{s}^{-1}\right)$ were, respectively, 2.0 and 7.2 times greater for the former.

$$
X(t)=\frac{X_{0} e^{\mu t}}{1-\left(\frac{X_{0}}{X_{m}}\right)\left(1-e^{\mu t}\right)}
$$

Additional models have been established to analyze the metabolic aspects of microalgal systems in their native ecosystems. Guven and Howard compiled a comprehensive review of mathematical and artificial neural network models of cyanobacterial growth in their natural freshwater habitats. ${ }^{123}$ Such information is applicable to microalgal phycocyanin production systems emulating optimal natural habitats. The isolation of a microalgal species from a model-predicted bloom will be an ideal candidate for the axenic species of a freshwater habitat-emulated bioreactor system. Native marine habitat growth modelling of phycocyaninproducing microalgae has also been researched. The symbiotic growth of cyanobacteria, purple and colourless bacteria in marine microbial mat communities has been analyzed and modelled by Wit et al. ${ }^{124}$ This work consolidates multiple models that take into account different species, metabolic types, and environmental parameters including oxygen concentration, total free sulfide, photosynthetic active radiation and near infrared radiation. Such a model may prove applicable to bioreactor systems opting for a polyculture environment with marine species.

The development of models that describe the metabolic ability of microalgae to remove nutrients from waste waters is pertinent to the environmental impact of microalgal cultures. Such models hold particular significance to phyco-valorization systems by allowing a further comprehension of a culture's capacity to utilize waste effluents. This information may in turn be used to determine optimal photobioreactor parameters for commercial 
production systems. A summary of models analyzing nutrient uptake by phycocyaninproducing microalgae is shown in Table S3 in the Supporting Information.

The most prevalent substrates modelled are nitrogen and organic carbon compounds. Most models utilize mass balance or reaction kinetic equation, and some account for substrate autoinhibition with Monod-type terms. Lu et al. present a unique model that accounts for the mass transfer process and the growth kinetics of alginate-entrapped cyanobacteria Anabaena $\mathrm{CH} 3$ in a batch reactor (Equations (3) and (4)), to predict the removal of nitrogenous compounds in wastewaters. ${ }^{121}$ The governing equations were cast in dimensionless form and solved by the method of explicit finite difference. The model could capture the mass transfer behaviour around a spherical bead and the diffusion process within the cell-containing gel. $\mathrm{Lu}$ et al. noted that immobilized microalgae could overcome some difficulties found with the application of suspended microalgae for wastewater treatment, namely maintaining monospecificity and separation of biomass from effluent before discharge. ${ }^{121}$ The challenge with immobilized cells however, is that these cells experience lower substrate concentrations within the gel (modelled by Equation (3)) than those in the bulk liquid (modelled by Equation (4)), because of diffusion limitations, which hinders the substrate consumption (and hence wastewater decontamination) rate. ${ }^{121}$ Dang et al. focussed on iron uptake rates (Equation (5)), as cyanobacteria have a relatively high iron requirement to sustain processes of photosynthetic and respiratory electron transfer and, in some cases, nitrogen fixation. ${ }^{125}$ The study found that the rate of iron uptake was lower for cells grown under conditions of lower iron availability, suggesting that cells adjusted by decreasing their maximum uptake rates $\left(\rho_{\max }\right)$ while maintaining a constant affinity $\left(K_{p}\right)$ for iron.

$$
\begin{aligned}
& \frac{\partial N_{g}^{*}}{\partial t^{*}}=\left(\frac{\partial^{2} N_{g}^{*}}{\partial r^{* 2}}+\frac{2}{r^{2}} \frac{\partial N_{g}^{*}}{\partial r^{*}}\right)-\phi^{2} \frac{N_{g}^{*}}{1+N_{g}^{*}} \\
& \frac{\partial N_{b}^{*}}{\partial t^{*}}=-3 \alpha \cdot B i\left(N_{b}^{*}-N_{s}^{*}\right)
\end{aligned}
$$




$$
\rho_{F e}=\rho_{\max } \frac{\left[\mathrm{Fe}(I I)^{\prime}\right]_{s S}}{K_{p}+\left[\mathrm{Fe}(I I)^{\prime}\right]_{s s}}
$$

The development of novel predicative models relating lighting parameters to the growth of cyanobacteria is an additional subject of current research interest. A comprehensive model combining the mechanisms of monodimensional radiative energy transfer by light and metabolic processes of $A$. platensis has been developed by Cornet et al. ${ }^{69,127}$ These works focused on establishing a simplified method for determining the optimal parallelepipedic photobioreactor system parameters for microalgal growth, which allows for a further application to systems of more complex geometries. More recently, a model was developed by Gorbunov et al. that explored the mechanism of non-photochemical quenching in cyanobacteria. ${ }^{128}$ Photobioreactor systems utilizing daylight as the illumination source will often be subject to extreme light intensities capable of damaging the culture. This model allows a further comprehension of the photoprotective mechanics employed by cyanobacteria under such conditions.

\section{Phyco-valorization: Integrated Resource Recovery}

The sustainable engineering practice of integrating a value recycling process within existing infrastructure is known as integrated resource recovery. ${ }^{129-131}$ Oftentimes, the addition of such a process has both the benefit of environmental remediation and of increased system economics efficiency. Phycoremediation technology has a significant amenability to resource recovery from a variety of waste streams. The idea for phycoremediation stems from the observation that cyanobacterial blooms are often stimulated by the hypertrophication of natural habitats by means of human/industrial waste disposal. ${ }^{132,133}$ Phycoremediation involves the integration of waste into bioreactors, where the microalgae acts to chelate metals, or to degrade unwanted compounds. ${ }^{83}$ Potential resources drawn from unused 
industrial waste streams or infrastructure include substrate sources, excess temperature control streams, $\mathrm{pH}$ adjusting materials, and available light.

A step further in the sustainable engineering practice is phyco-valorization: the exploitation of microalgae and microalgal chemicals as valuable products. Figure 1 illustrates an example from literature where flue gases are treated in photobioreactors, leading to the production of valuable algal products after a biomass processing stage. Here, the authors propose the use of extremophilic algae when using flue gases directly or after concentration of acidic compounds. These species not only tolerate extreme environmental conditions but require such conditions to thrive, which becomes a major advantage since these cultures are less affected by outdoor contamination. ${ }^{65}$ Examples are the cultivation of thermophilic cyanobacteria or species growing in diluted sulfuric acid (i.e. acidophilic); the red algae Cyanidium caldarium and G. sulphuraria are both thermo- and acidophilic. ${ }^{65}$ The process of microalgal product recovery involves separation of the algal biomass from the liquid medium, still containing nutrients that can be recycled, followed by extraction of the desired product from the biomass using techniques such as drying, extraction and esterification.

The harvesting of commercially viable components from the phycoremediation process has been suggested as one way to increase the feasibility of this technology. ${ }^{28,134}$ Through optimizing the production of the high-valued pigment phycocyanin in a phycoremediation process, the process may be able to advance into a system of phycovalorization, posing both opportunities for environmental remediation and increased profits for potential manufacturing facilities. This concept may also apply to systems where phycocyanin producing microalgae may be present although not encouraged, such as in water purification applications. Common to water quality programs is the detection of phycocyanin concentration due to its correlation with increased toxicity imparted by cyanobacteria. ${ }^{61,62}$ In this scenario, the resources spent in detecting and removing phycocyanin-producing 
microalgae may be recuperated through isolation of the available phycocyanin. Further research is required to evaluate the prospect of isolating phycocyanin from the water purification process in the event of a toxic and phycocyanin-rich cyanobacteria bloom.

\section{Reaching Optimal Production Parameters via Phyco-valorization}

In this section, the same parameters that were discussed as necessary to monitor and control for optimal phycocyanin productivity in dedicated systems are discussed again in the context of phyco-valorization. That is, how are these parameters controlled in a system that utilizes waste streams or residual resources to achieve the optimal (or near optimal) conditions of dedicated systems (summarized in Table 4).

\section{Lighting Conditions for Phyco-valorization}

When considering the development of a phycocyanin production system, the integration into a functioning venture can greatly improve overall efficiency. In this scenario, construction of a microalgal phycocyanin production bioreactor should be accompanied by a thorough analysis of available light sources. Alternatively, new manufacturing facilities can be designed to optimally integrate microalgal phycocyanin production with the other manufacturing activity (e.g. horticulture) in a way that maximizes overall efficiency.

Numerous industries utilize outdoor production facilities with ample natural sunlight covering, such as agricultural or concrete manufacturing plants. ${ }^{135,136}$ Such production plants could take advantage of the light exposure by integrating a photobioreactor system into the existing infrastructure for algal phycocyanin production. This would be especially applicable to facilities producing waste effluents that could function in other areas of the bioreactor system such as medium and $\mathrm{pH}$ adjustment. Although natural daylight provides the greatest light intensity with wide ranging spectrum, attention should be drawn to its drawbacks. Sunlight reaches maximum intensity levels that have been shown to decrease cyanobacteria 
production rates. ${ }^{137}$ This may be due to the surface of the culture experiencing light intensities exceeding the optimal threshold.

Currently functioning artificial lighting system facilities is another option for photobioreactor system integration. Artificial lighting provides a readily controlled light source with constant intensity and spectrum. However, the excessive cost of powering artificial lighting systems has resulted in their limited use. Despite this, a number of industries currently benefit from the use of artificial lighting systems, such as indoor horticultural practices. One study reported that in the Netherlands, 19\%, or about 2000 ha, of the total glasshouse area is equipped with supplementary assimilation light. ${ }^{138}$ Literature has also suggested the beneficial effect of unifying microalgal production systems simultaneously with aquaponic systems, many of which utilize artificial lighting. ${ }^{139}$

The artificial lighting equipment used in industry has specific light intensity and spectrum corresponding with the particular production system. In horticultural practices, the growth response of plants to different wavelengths differs, and as such these artificial lighting systems are designed to maximize Photosynthesis Active Radiation (PAS). The selection of suitable lamps is also made in a manner that maximizes the Photosynthetic Photon Flux to wattage ratio $(\mathrm{PPF} / \mathrm{W})$; this measure is greatest for high pressure sodium lamps, and is lowest for incandescent and halogen lamps (GE Lighting, http://www.gelighting.com/LightingWeb/kor/images/Horticulture_Lighting_Brochure_EN_tc m563-12710.pdf). In one study on tomato culturing, it was found that high productivity requires dominance of the $600-700 \mathrm{~nm}$ red portion of the irradiation spectrum. ${ }^{140}$ The same study also reports that in cucumber culturing, blue or green irradiation alone do not promote development; rather a balance between blue, green and red lighting is required.

By adapting a microalgal phycocyanin production system to a facility with optimal artificial lighting conditions, a significant increase in lighting utilization can be achieved. 
However, since the lighting conditions are optimized for other purposes, the microalgal cultivation system may not operate at its optimal lighting parameters (Table 2). Thus, the optimization of other process parameters that balance this shortcoming would be required.

\section{Climatic and Nutritional Conditions for Phyco-valorization}

Common to manufacturing facilities is the utilization of energy sources for heating and cooling duties. ${ }^{141}$ These temperature control processes have led to the development of sustainable engineering design of heat recovery systems. Such systems aim to identify and take advantage of opportunities throughout the facility to reuse residual heat. Overall, the efficiency of the system is increased by reducing energy consumption. ${ }^{142}$ An opportunity for heat recovery may be realized through the integration of a microalgal bioreactor. Many of the notable potential microalgal species have had maximal phycocyanin productivities recorded at increasingly warm temperatures (Table 2). Two of the most productive species, $A$.

platensis and G. sulphuraria, have had their maximum phycocyanin productivity recorded at or above $30^{\circ} \mathrm{C} .{ }^{66,74,89}$ Considering that only selected climates are able to maintain such conditions for suitable lengths of time, bioreactor temperature control is necessary to maintain optimal production rates. Continuous utilization of a residual heat stream to apply further control of the bioreactor temperature may result in increased spent energy value. An economic analysis of this energy recovery system is required on a case-by-case basis to determine viability.

Controlling photobioreactor media $\mathrm{pH}$ at or near optimal values (Table 2) is necessary to ensure the optimal culture growth and phycocyanin productivity. The use of highly alkaline or acidic compounds to adjust system $\mathrm{pH}$ is a commonly used method to achieve this control; however, significant costs are imparted. Thus, when developing a microalgal phycocyanin production system, more efficient measures of controlling $\mathrm{pH}$ should be explored. A primary consideration should be the integration of local untreated or waste- 
derived water source as the basis of system media. This allows for overall reduction of $\mathrm{pH}$ control costs in two possible ways - the selection of a culture species amenable to the $\mathrm{pH}$ of the water source, or the selection of a water source with a $\mathrm{pH}$ requiring minimal adjustment. The wide range of viable $\mathrm{pH}$ levels for optimal microalgal growth (Table 2) may lend itself to the selection of an agreeable species.

Although adjustment of the bioreactor $\mathrm{pH}$ may be minimized through the use of suitable local untreated or waste-derived water, the production of algal metabolites throughout the process will ultimately drift the system $\mathrm{pH}$ away from optimal levels. Thus, an analysis of possible $\mathrm{pH}$ adjustment agents should be realized. The utilization of highly acidic or alkaline system effluents is a principal opportunity. The viability of recycling these streams into useful $\mathrm{pH}$ adjustment agents has been previously demonstrated; for example, Atkinson isolated organic acids using bipolar membrane electrolysis. ${ }^{143}$ A microalgal phycocyanin production system that is able to maintain $\mathrm{pH}$ levels using an untreated effluent may provide a highly economic means of treating these waste streams, as such streams are often difficult to dispose of due to the magnitude of $\mathrm{pH}$.

The significant cost of standard laboratory grade media formulations, along with the wide range of native substrates identified for phycocyanin-producing microorganisms, has propelled a search for economic media alternatives. ${ }^{144}$ Wastewater and other waste effluents are highly economic potential media sources. Furthermore, while serving as media for microalgal phycocyanin production, the use of a waste effluent-based media brings the additional function of environmental remediation.

Current research has demonstrated the feasibility of using waste effluent from an assortment of industries as bioreactor substrate media. Vetayasuporn determined the viability of rice noodle factory-derived wastewater for use as substrate media for the growth of $A$. platensis. ${ }^{145}$ Other food-based industrial effluents have also been identified as promising 
nutrient sources, including dairy and brewery waste streams. ${ }^{146-148}$ The use of agricultural swine wastewater as medium for A. platensis growth has also proven successful. ${ }^{149,150}$ Similarly, aquaculture waste effluent has been identified as a potential microalgae media source. ${ }^{139}$ A study by Dunn et al. found industrial tannery wastewater to be an acceptable substrate for A. platensis production. ${ }^{151}$ The use of municipal wastewater as a viable media for microalgal growth has been demonstrated by numerous studies. ${ }^{152-154}$ El-Bestawy confirmed that the cyanobacterium Tolypothrix ceytonica, Anabaena variabilis and Anabaena oryzae have adequate growth in highly polluted industrial-residential wastewater. ${ }^{155}$ Caution should be exercised, however, when looking to produce food-grade microalgal products, as contaminants from the wastewater may pose a safety risk if not completely removed from the isolated final product.

A further waste source for phycocyanin production system media is industrial flue gas, which is known to contain high $\mathrm{CO}_{2}$ concentrations, such as that from ethanol distillation, ${ }^{83}$ and to also contain $\mathrm{NO}_{\mathrm{x}}$ (which forms nitrate in solution, acting as additional electron acceptor ${ }^{156}$ ), such as power plant flue gases. ${ }^{157}$ Recent research has shown that a variety of phycocyanin-producing cyanobacteria have favourable potentials for using industrial flue gas as carbon substrate source. ${ }^{156-158}$ Arata et al. studied the possibility of simultaneously feeding $\mathrm{CO}_{2}$ and $\mathrm{NO}_{\mathrm{x}}$ gases during cultivation of $A$. platensis, and found best results when using opportune dosages in a fed-batch reactor. ${ }^{157}$ Kumar et al. reviewed the literature on $\mathrm{CO}_{2}$ sequestration in photobioreactors, and concluded that based on system requirements for high solids to volume ratio, mixing, mass transfer, scalability and ease of operation, an airlift reactor integrated with a tubular loop reactor is most promising option. ${ }^{158}$ This hybrid design exploits the advantages of the two different type of reactor, and one overcomes the disadvantage of the other. ${ }^{158}$ 


\section{Economic Evaluation of Existing Infrastructure Integration}

The costs associated with novel microalgal phycocyanin production systems has been previously reviewed by Vonshak. ${ }^{159}$ Adjusted for inflation, the capital cost of a pond system producing 40 tonnes of biomass annually was determined to range between U.S. $\$ 863,580$ $\$ 2,633,000$ (in 1992 value). Similarly, the annual operating cost was determined to range between U.S. $\$ 419,116$ - \$1,754,205 (in 1992 value). Through the application of infrastructure integration, the costs can be greatly reduced. An economic analysis of a similar microalgal bioreactor-based production system determined media to constitute approximately $17.5 \%$ of the total operating costs. ${ }^{160}$ Thus, a substantial reduction in production costs may be achieved through the use of waste effluent nutrient-based media and carbon dioxide derived from flue gas. Recycling thermal energy from other industrial processes can also allow for a significant reduction in production cost. Optimal temperature control of the system was determined to contribute $8 \%$ of the total operating costs in the economic analysis by Li et al. ${ }^{160}$ Capital costs may be reduced through integrating the construction of a microalgal phycocyanin production facility. Manufacturing facilities amenable to such integration are those that could provide a means for the previously discussed operating cost reductions. Building area and land costs have been estimated to range from $8.9 \%-30.6 \%$ of the capital costs. ${ }^{159,160}$

In order to provide a reliable economic evaluation of a microalgal phycocyanin production system, a comprehensive cost analysis is required. The procedure for such an analysis would entail the construction, operation, and evaluation of a large-scale pilot bioreactor system. The establishment of a pilot-scale operation may be accomplished applying growth models and optimal system parameters established in recent literature. Further optimization for a specific location and production volume may be accomplished by localized pilot system evaluation. This system would optimally be operated for multiple years 
in order to determine the effect of seasonal environmental transitions. Upon system optimization, the established parameters can be scaled to larger pilot systems. The amount of pilot-scale testing is relative to the degree of reliability required for the final production system. Li et al. ${ }^{160}$ demonstrate a comprehensive analysis of system parameters to be established for optimal commercial microalgae production.

\section{Conclusions}

Microalgae constitute a fundamental component of the biosphere through their contribution of nutrient and sunlight energy transforming mechanisms. As a means of nitrogen storage and light energy capture, the pigment phycocyanin is a necessary compound for numerous microalgae to continue their ecologic role. This innate function of microalgae may be exploited through the culturing of species amenable to industrial practice. The recent surge of interest in the application and production of microalgal phycocyanin has demonstrated the promising economic outlook of photobioreactor systems. In order to maximize the potential of such systems, several strategies to enhance phycocyanin productivities are advocated. A primary consideration of a microalgal phycocyanin production system is the species present in the culture. Beyond agreeing with local climate conditions, additional factors to consider include attributes of culture trophic mode as well as interspecies relations. Research has demonstrated that the phycocyanin productivities of various species are dependent upon the system lighting, climatic conditions, substrate component concentrations, as well as the bioreactor operational mode. Both previous research and further case analysis may be applied to balance the factors contributing to overall system productivity. An economically sound approach to achieving system optimization is the modelling of metabolic kinetics and subsequent scaling to desired production. Several models have been previously developed and may be used as benchmarks for this endeavour. A further approach for improving the 
viability of microalgal phycocyanin production systems would be their application in integrated resource recovery. Previous efforts have determined the viability of microalgae in environmental remediation initiatives. Through the incorporation of phycocyanin productivity optimization principles into a phycoremediation process, the harvesting of phycocyanin may valorize otherwise wasted resources. The simultaneous economic potential and environmentally-forward concept of phyco-valorization through phycocyanin production is a promising application of microalgal biotechnology awaiting further development for industrial implementation.

\section{Acknowledgements}

This work was supported by funding from the Ontario Ministry of Agriculture, Food and Rural Affairs (LAAIR2014-5089).

\section{References}

1. Bellou S, Baeshen MN, Elazzazy AM, Aggeli D, Sayegh F, and Aggelis G, Microalgal lipids biochemistry and biotechnological perspectives. Biotechnol Adv 32:1476-93 (2014).

2. Gerardo ML, Oatley-Radcliffe DL, and Lovitt RW, Integration of membrane technology in microalgae biorefineries. J Memb Sci 464:86-99 (2014).

3. Harun R, Singh M, Forde GM, and Danquah MK, Bioprocess engineering of microalgae to produce a variety of consumer products. Renew Sustain Energy Rev 14: 1037-47 (2010).

4. Honda R, Boonnorat J, Chiemchaisri C, Chiemchaisri W, and Yamamoto K, Carbon dioxide capture and nutrients removal utilizing treated sewage by concentrated microalgae cultivation in a membrane photobioreactor. Bioresour Technol 125:59-64 (2012).

5. Liu T, Wang J, Hu Q, Cheng P, Ji B, Liu J, Chen Y, Zhang W, Chen X, Chen L, Gao $\mathrm{L}$, Ji C, and Wang $\mathrm{H}$, Attached cultivation technology of microalgae for efficient biomass feedstock production. Bioresour Technol 127:216-22 (2013). 
6. Markou G, and Nerantzis E, Microalgae for high-value compounds and biofuels production: A review with focus on cultivation under stress conditions. Biotechnol Adv 31:1532-42 (2013).

7. Norsker NH, Barbosa MJ, Vermuë MH, and Wijffels RH, Microalgal production - A close look at the economics. Biotechnol Adv 29:24-7 (2011).

8. Ruiz-Martinez A, Martin Garcia N, Romero I, Seco A, and Ferrer J, Microalgae cultivation in wastewater: Nutrient removal from anaerobic membrane bioreactor effluent. Bioresour Technol 126:247-53 (2012).

9. Kawaguchi K, Algae biomass: production and use, in Algae biomass: production and use, ed by Soeder CJ, and Gedaliah S. Elsevier Biomedical Press, Amersterdam, (1980).

10. Soong P, Production and development of Chlorella and Spirulina in Taiwan, in Algae biomass: production and use, ed by Shelef G, and Soeder C. Elsevier Biomedical Press, Amersterdam, pp 97-113 (1980).

11. Bai M Der, Cheng $\mathrm{CH}$, Wan HM, and Lin YH, Microalgal pigments potential as byproducts in lipid production. J Taiwan Inst Chem Eng 42:783-6 (2011).

12. Jin E, Polle JEW, Lee HK, Hyun SM, and Chang M, Xanthophylls in microalgae: From biosynthesis to biotechnological mass production and application. $J$ Microbiol Biotechnol 13:165-74 (2003).

13. Lorenz RT, and Cysewski GR, Commercial potential for Haematococcus microalgae as a natural source of astaxanthin. Trends Biotechnol 18:160-7 (2000).

14. Milledge JJ, Commercial application of microalgae other than as biofuels: A brief review. Rev Environ Sci Biotechnol 10:31-41 (2011).

15. Mulders KJM, Lamers PP, Martens DE, and Wijffels RH, Phototrophic pigment production with microalgae: Biological constraints and opportunities. J Phycol 50:229-42 (2014).

16. Pignolet $\mathrm{O}$, Jubeau S, Vaca-Garcia $\mathrm{C}$, and Michaud P, Highly valuable microalgae: Biochemical and topological aspects. J Ind Microbiol Biotechnol 40:781-96 (2013).

17. Singh J, and Gu S, Commercialization potential of microalgae for biofuels production. Renew Sustain Energy Rev 14:2596-610 (2010).

18. Eriksen NT, Production of phycocyanin--a pigment with applications in biology, biotechnology, foods and medicine. Appl Microbiol Biotechnol 80:1-14 (2008).

19. MacColl R, Cyanobacterial Phycobilisomes. J Struct. Biol. 124:311-34 (1998).

20. Dhruv S, Mani I, and Iyer U, Spirulina and Its Therapeutic Implications as a Food Product, in Spirulina in Human Nutrition and Health, ed by Gershwin ME, and Belay A. CRC Press, Boca Raton, pp 51-70 (2007). 
21. Liang S, Liu X, Chen F, and Chen Z, Current microalgal health food R \& D activities in China. Hydrobiologia 512:45-8 (2004).

22. Azarpira H, Dhumal K, and Pondhe G, Application of phycoremediation technology in the treatment of sewage water to reduce pollution load. Adv Environ Biol 8:2419-23 (2014).

23. Hanumantha Rao P, Ranjith Kumar R, Raghavan B, Subramanian V, and Sivasubramanian V, Application of phycoremediation technology in the treatment of wastewater from a leather-processing chemical manufacturing facility. Water SA 37:714 (2011).

24. Kotteswari M, Murugesan S, and R RK, Phycoremediation of Dairy Effluent by using the Microalgae Nostoc sp. Int J Environ Res Dev 2:35-43 (2012).

25. Olguín EJ, and Sánchez-Galván G, Heavy metal removal in phytofiltration and phycoremediation: The need to differentiate between bioadsorption and bioaccumulation. $N$ Biotechnol 30:3-8 (2012).

26. Prajapati SK, Kaushik P, Malik A, and Vijay VK, Phycoremediation and biogas potential of native algal isolates from soil and wastewater. Bioresour Technol 135:232-8 (2013).

27. Rawat I, Ranjith Kumar R, Mutanda T, and Bux F, Dual role of microalgae: Phycoremediation of domestic wastewater and biomass production for sustainable biofuels production. Appl Energy 88:3411-24 (2011).

28. Sankaran K, Premalatha M, Vijayasekaran M, and Somasundaram V, DEPHY project: Distillery wastewater treatment through anaerobic digestion and phycoremediation-A green industrial approach. Renew Sustain Energy Rev 37:634-643 (2014).

29. Sivasubramanian V, Subramanian V V., Raghavan BG, and Ranjithkumar R, Large scale phycoremediation of acidic effluent from an alginate industry. ScienceAsia 35:220-6 (2009).

30. Solovchenko A, Pogosyan S, Chivkunova O, Selyakh I, Semenova L, Voronova E, Scherbakov P, Konyukhov I, Chekanov K, Kirpichnikov M, and Lobakova E, Phycoremediation of alcohol distillery wastewater with a novel Chlorella sorokiniana strain cultivated in a photobioreactor monitored on-line via chlorophyll fluorescence. Algal Res 6:234-241 (2014).

31. Zainal A., Yaakob Z., Takriff MS., Rajkumar R., and Ghani JA., Phycoremediation in anaerobically digested Palm Oil Mill Effluent using cyanobacterium, Spirulina platensis. J Biobased Mater Bioenergy 6:704-9 (2012).

32. Komárek J, Kaštovský J, Mareš J, and Johansen JR, Taxonomic classification of cyanoprokaryotes (cyanobacterial genera) 2014, using a polyphasic approach. Preslia 86:295-335 (2014). 
33. Subhashini J, Mahipal SVK, Reddy MC, Reddy MM, Rachamallu A, and Reddanna P, Molecular mechanisms in C-Phycocyanin induced apoptosis in human chronic myeloid leukemia cell line-K562. Biochem Pharmacol 68:453-62 (2004).

34. Ahsan M, Habib B, Parvin M, Huntington TC, and Hasan MR, A review on culture, production and use of spirulina as food for humans and feeds for domestic animals. FAO Fisheries and Aquaculture Circular 1034:1-27 (2008).

35. Rodríguez-Sánchez R, Ortiz-Butrón R, Blas-Valdivia V, Hernández-García A, and Cano-Europa E, Phycobiliproteins or C-phycocyanin of Arthrospira (Spirulina) maxima protect against $\mathrm{HgCl}_{2}$-caused oxidative stress and renal damage. Food Chem 135:2359-65 (2012).

36. Ravi M, Lata DS, Azharuddin S, and Paul S, The beneficial effects of spirulina focusing on its immunomodulatory and antioxidant properties. Nutr Diet Suppl 2010:7383 (2010).

37. Murugan T. R, Screening for Antifungal and Antiviral activity of C-phycocyanin from Spirulina Platensis. J Pharm Res 4:4161-3 (2011).

38. Bhat VB, and Madyastha KM, C-phycocyanin: a potent peroxyl radical scavenger in vivo and in vitro. Biochem Biophys Res Commun 275:20-5 (2000).

39. Ou Y, Zheng S, Lin L, Jiang Q, and Yang X, Protective effect of C-phycocyanin against carbon tetrachloride-induced hepatocyte damage in vitro and in vivo. Chem Biol Interact 185:94-100 (2010).

40. Roy KR, Nishanth RP, Sreekanth D, Reddy GV, and Reddanna P, C-Phycocyanin ameliorates 2-acetylaminofluorene induced oxidative stress and MDR1 expression in the liver of albino mice. Hepatol Res 38:511-20 (2008).

41. Sun L, Wang S, Chen L, and Gong X, Promising fluorescent probes from phycobiliproteins. IEEE J Sel Top Quantum Electron 9:177-88 (2003).

42. Randolph K, Wilson J, Tedesco L, Li L, Pascual DL, and Soyeux E, Hyperspectral remote sensing of cyanobacteria in turbid productive water using optically active pigments, chlorophyll a and phycocyanin. Remote Sens Environ 112:4009-19 (2008).

43. Bastien C, Cardin R, Veilleux E, Deblois C, Warren A, and Laurion I, Performance evaluation of phycocyanin probes for the monitoring of cyanobacteria. $J$ Environ Monit 13:110-8 (2011).

44. Brient L, Lengronne M, Bertrand E, Rolland D, Sipel A, Steinmann D, Baudin I, Legeas M, Le Rouzic B, and Bormans M, A phycocyanin probe as a tool for monitoring cyanobacteria in freshwater bodies. J Environ Monit 10:248-55 (2008).

45. Chang DW, Hobson P, Burch M, and Lin TF, Measurement of cyanobacteria using invivo fluoroscopy - Effect of cyanobacterial species, pigments, and colonies. Water Res 46:5037-48 (2012). 
46. Izydorczyk K, Tarczynska M, Jurczak T, Mrowczynski J, and Zalewski M, Measurement of phycocyanin fluorescence as an online early warning system for cyanobacteria in reservoir intake water. Environ Toxicol 20:425-30 (2005).

47. McQuaid N, Zamyadi A, Prévost M, Bird DF, and Dorner S, Use of in vivo phycocyanin fluorescence to monitor potential microcystin-producing cyanobacterial biovolume in a drinking water source. J Environ Monit 13:455-63 (2011).

48. Seppälä J, Ylöstalo P, Kaitala S, Hällfors S, Raateoja M, and Maunula P, Ship-ofopportunity based phycocyanin fluorescence monitoring of the filamentous cyanobacteria bloom dynamics in the Baltic Sea. Estuar Coast Shelf Sci 73:489-500 (2007).

49. Wlodarczyk LM, Moldaenke C, and Fiedor L, Fluorescence as a probe for physiological integrity of freshwater cyanobacteria. Hydrobiologia 695:73-81 (2012).

50. Zamyadi A, McQuaid N, Prévost M, and Dorner S, Monitoring of potentially toxic cyanobacteria using an online multi-probe in drinking water sources. J Environ Monit 14:579-88 (2012).

51. Kronick MN, and Grossman PD, Immunoassay techniques with fluorescent phycobiliprotein conjugates. Clin Chem 29:1582-6 (1983).

52. Glazer AN, Phycobiliproteins - a family of valuable, widely used fluorophores. $J$ Appl Phycol 6:105-12 (1994).

53. Aráoz R, Lebert M, and Häder DP, Electrophoretic applications of phycobiliproteins. Electrophoresis 19:215-9 (1998).

54. Downes M, and Hall J, A sensitive fluorometric technique for the measurement of phycobilin pigments and its application to the study of marine and freshwater picophytoplankton in oligotrophic environments. J Appl Phycol 10:357-63 (1998).

55. Li Y, Yang H, Cao F, Zhao X, and Wang J, The stability of C-phycocyanin doped silica biomaterials in UV irradiation. J Wuhan Univ Technol Mater Sci Ed 24:852-6 (2009).

56. Glazer AN, and Stryer L, Phycofluor probes. Trends Biochem Sci 9:423-7 (1984).

57. Naidu KA, Sarada R, Manoj G, Khan MY, Swamy MM, Viswanatha S, Murthy KN, Ravishankar GA, and Srinivas L, Toxicity Assessment Of Phycocyanin - A Blue Colorant From Blue Green Alga Spirulina platensis. Food Biotechnol 13:51-66 (1999).

58. U.S. Department of Food and Drug Administration, Listing of Color Additives Exempt From Certification; Spirulina Extract. (2013). http://www.gpo.gov/fdsys/pkg/FR2013-08-13/html/2013-19550.htm [accessed 7 August 2014]. 
59. Emerson R, and Lewis CM, The photosynthetic efficiency of phycocyanin in Chroococcus, and the problem of carotenoid participation in photosynthesis. J Gen Physiol 25:579-95 (1942).

60. Kuddus M, Singh P, Thomas G, and Al-Hazimi A, Recent developments in production and biotechnological applications of c-phycocyanin. Biomed Res Int 2013 (2013).

61. Li L, and Song K, Remote sensing of freshwater cyanobacteria: An extended IOP Inversion Model of Inland Waters (IIMIW) for partitioning absorption coefficient and estimating phycocyanin. Remote Sens Environ 157 (2015).

62. Song K, Li L, Li Z, Tedesco L, Hall B, and Shi K, Remote detection of cyanobacteria through phycocyanin for water supply source using three-band model. Ecol Inform 15:22-33 (2013).

63. Herrera A, Boussiba S, Napoleone V, and Hohlberg A, Recovery of c-phycocyanin from the cyanobacterium Spirulina maxima. J Appl Phycol 1:325-31 (1989).

64. Chaiklahan R, Chirasuwan N, Loha V, Tia S, and Bunnag B, Separation and purification of phycocyanin from Spirulina sp. using a membrane process. Bioresour Technol 102:7159-64 (2011).

65. Pulz O, and Gross W, Valuable products from biotechnology of microalgae. Appl Microbiol Biotechnol 65:635-48 (2004).

66. Chen CY, Kao PC, Tsai CJ, Lee DJ, and Chang JS, Engineering strategies for simultaneous enhancement of C-phycocyanin production and $\mathrm{CO}_{2}$ fixation with Spirulina platensis. Bioresour Technol 145:307-12 (2013).

67. Walter A, Carvalho J, and Soccol V, Study of phycocyanin production from Spirulina platensis under different light spectra. Brazilian Arch Bio Tech 54:675-82 (2011).

68. Zeng X, Danquah MK, Zhang S, Zhang X, Wu M, Chen XD, Ng IS, Jing K, and Lu Y, Autotrophic cultivation of Spirulina platensis for $\mathrm{CO}_{2}$ fixation and phycocyanin production. Chem Eng J 183:192-7 (2012).

69. Cornet JF, Dussap CG, Cluzel P, and Dubertret G, A structured model for simulation of cultures of the cyanobacterium Spirulina platensis in photobioreactors: II. Identification of kinetic parameters under light and mineral limitations. Biotechnol Bioeng 40:826-34 (1992).

70. Chen F, and Zhang Y, High cell density mixotrophic culture of Spirulina platensis on glucose for phycocyanin production using a fed-batch system. Enzyme Microb Technol 20:221-4 (1997).

71. Chen HB, Wu JY, Wang CF, Fu CC, Shieh CJ, Chen CI, Wang CY, and Liu YC, Modeling on chlorophyll a and phycocyanin production by Spirulina platensis under various light-emitting diodes. Biochem Eng J 53:52-6 (2010). 
72. Zhang XW, Zhang YM, and Chen F, Kinetic models for phycocyanin production by high cell density mixotrophic culture of the microalga spirulina platensis. $J$ Ind Microbiol Biotechnol 21:283-8 (1998).

73. Morales E, Rodríguez M, García D, Loreto C, and Marco E, Crecimiento, producción de pigmentos y exopolisacáridos de la cianobacteria Anabaena sp. PCC 7120 en función del pH y CO 2 . Interciencia 27:373-8 (2002).

74. Graverholt OS, and Eriksen NT, Heterotrophic high-cell-density fed-batch and continuous-flow cultures of Galdieria sulphuraria and production of phycocyanin. Appl Microbiol Biotechnol 77:69-75 (2007).

75. Kenekar A, and Deodhar M, Effect of Varying Physicochemical Parameters on the Productivity and Phycobiliprotein Content of Indigenous Isolate Geitlerinema sulphureum. Biotechnology 12:146-54 (2013).

76. Singh NK, Parmar A, and Madamwar D, Optimization of medium components for increased production of C-phycocyanin from Phormidium ceylanicum and its purification by single step process. Bioresour Technol 100:1663-9 (2009).

77. Takano H, Arai T, Hirano M, and Matsunaga T, Effects of intensity and quality of light on phycocyanin production by a marine cyanobacterium Synechococcus sp. NKBG 042902. Appl Microbiol Biotechnol 43:1014-8 (1995).

78. Spolaore P, Joannis-Cassan C, Duran E, and Isambert A, Commercial applications of microalgae. J Biosci Bioeng 101:87-96 (2006).

79. Richmond A, and Grobbelaar JU, Factors affecting the output rate of Spirulina platensis with reference to mass cultivation. Biomass 10:253-64 (1986).

80. Chojnacka K, and Zielińska A, Evaluation of growth yield of Spirulina (Arthrospira) sp. in photoautotrophic, heterotrophic and mixotrophic cultures. World J Microbiol Biotechnol 28:437-45 (2012).

81. Marquez FJ, Sasaki K, Kakizono T, Nishio N, and Nagai S, Growth characteristics of Spirulina platensis in mixotrophic and heterotrophic conditions. J Ferment Bioeng 76:408-10 (1993).

82. Trabelsi L, Ben Ouada H, Zili F, Mazhoud N, and Ammar J, Evaluation of Arthrospira platensis extracellular polymeric substances production in photoautotrophic, heterotrophic and mixotrophic conditions. Folia Microbiol (Praha) 58:39-45 (2013).

83. Fouilland E, Biodiversity as a tool for waste phycoremediation and biomass production. Rev Environ Sci Bio/Technology 11:1-4 (2012).

84. Costa V, De Morais JA, Dalcanton F, Reichert Da Cruz C, and Durante AJ, Simultaneous cultivation of Spirulina platensis and the toxigenic cyanobacteria Microcystis aeruginosa. Zeitschrift fur Naturforsch - Sect C J Biosci 61c:105-10 (2006). 
85. Rastogi RP, and Sinha RP, Biotechnological and industrial significance of cyanobacterial secondary metabolites. Biotechnol Adv 27:521-39 (2009).

86. Rabinowitch E, The Photosynthetic Pigments, in Photosynthesis, Wiley, New York (1969).

87. Rodríguez H, Rivas J, Guerrero MG, and Losada M, Enhancement of phycobiliprotein production in nitrogen-fixing cyanobacteria. J Biotechnol 20:263-70 (1991).

88. Chaneva G, Furnadzhieva S, Minkova K, and Lukavsky J, Effect of light and temperature on the cyanobacterium Arthronema africanum - a prospective phycobiliprotein-producing strain. J Appl Phycol 19:537-44 (2007).

89. Colla LM, Oliveira Reinehr C, Reichert C, and Costa JA V, Production of biomass and nutraceutical compounds by Spirulina platensis under different temperature and nitrogen regimes. Bioresour Technol 98:1489-93 (2007).

90. Edwards MR, Hauer C, Stack RF, Eisele LE, and MacColl R, Thermophilic Cphycocyanin: Effect of temperature, monomer stability, and structure. Biochim Biophys Acta - Bioenerg 1321:157-64 (1997).

91. Quesada A, Vincent WF, and Lean DRS, Community and pigment structure of Arctic cyanobacterial assemblages: The occurrence and distribution of UV-absorbing compounds. FEMS Microbiol Ecol 28:315-23 (1999).

92. Ogbonda $\mathrm{KH}$, Aminigo RE, and Abu GO, Influence of temperature and $\mathrm{pH}$ on biomass production and protein biosynthesis in a putative Spirulina sp. Bioresour Technol 98:2207-11 (2007).

93. Markou G, Vandamme D, and Muylaert K, Microalgal and cyanobacterial cultivation: The supply of nutrients. Water Res 65:186-202 (2014).

94. Jin H-F, Lim B-R, and Lee K, Influence of nitrate feeding on carbon dioxide fixation by microalgae. J Environ Sci Health A Tox Hazard Subst Environ Eng 41:2813-24 (2006).

95. Szalontai B, and Csatorday K, Changes in phycocyanin-carotenoid association during nitrate starvation of Anacystis nidulans. Biochem Biophys Res Commun 88:1294-300 (1979).

96. Liotenberg S, Campbell D, Rippka R, Houmard J, and de Marsac NT, Effect of the Nitrogen Source on Phycobiliprotein Synthesis and Cell Reserves in A Chromatically Adapting Filamentous Cyanobacterium. Microbiol 142 :611-22 (1996).

97. De Lorimier RM, Smith RL, and Stevens SE, Regulation of phycobilisome structure and gene expression by light intensity. Plant Physiol 98:1003-10 (1992).

98. Markou G, Vandamme D, and Muylaert K, Using natural zeolite for ammonia sorption from wastewater and as nitrogen releaser for the cultivation of Arthrospira platensis. Bioresour Technol 155:373-78 (2014). 
99. Depraetere O, Foubert I, and Muylaert K, Decolorisation of piggery wastewater to stimulate the production of Arthrospira platensis. Bioresour Technol 148:366-72 (2013).

100. Markou G, Depraetere O, Vandamme D, and Muylaert K, Cultivation of Chlorella vulgaris and Arthrospira platensis with Recovered Phosphorus from Wastewater by Means of Zeolite Sorption. Int J Mol Sci 16:4250-64 (2015).

101. Allen MM, and Stanier RY, Selective isolation of blue-green algae from water and soil. J Gen Microbiol 51:203-9 (1968).

102. Borowitzka MA, Commercial production of microalgae: ponds, tanks, tubes and fermenters. J Biotechnol 70:313-21 (1999).

103. Vasumathi KK, Premalatha M, and Subramanian P, Parameters influencing the design of photobioreactor for the growth of microalgae. Renew Sustain Energy Rev 16:544350 (2012)

104. Jiménez C, Cossío BR, Labella D, and Niell FX, The feasibility of industrial production of Spirulina (Arthrospira) in Southern Spain. Aquaculture 217:179-90 (2003).

105. Moreno J, Vargas MÁ, Rodríguez H, Rivas J, and Guerrero MG, Outdoor cultivation of a nitrogen-fixing marine cyanobacterium, Anabaena sp. ATCC 33047. Biomol Eng 20:191-7 (2003).

106. Pushparaj B, Pelosi E, Tredici MR, Pinzani E, and Materassi R, An integrated culture system for outdoor production of microalgae and cyanobacteria. J Appl Phycol 9:1139 (1997).

107. Marquez FJ, Sasaki K, Nishio N, and Nagai S, Inhibitory effect of oxygen accumulation on the growth of Spirulina platensis. Biotechnol Lett 17:225-8 (1995).

108. Gregersen L, and Jørgensen SB, Supervision of fed-batch fermentations. Chem Eng J 75:69-76 (1999).

109. Vieira Costa JA, Colla LM, and Duarte Filho PF, Improving Spirulina platensis biomass yield using a fed-batch process. Bioresour Technol 92:237-41 (2004).

110. Chaiklahan R, Chirasuwan N, Siangdung W, Paithoonrangsarid K, and Bunnag B, Cultivation of spirulina platensis using pig wastewater in a semi-continuous process. $J$ Microbiol Biotechnol 20:609-14 (2010).

111. Kumar D, Rai J, and Gaur JP, Removal of metal ions by Phormidium bigranulatum (Cyanobacteria)-dominated mat in batch and continuous flow systems. Bioresour Technol 104:202-7 (2012).

112. Morist A, Montesinos JL, Cusidó JA, and Gòdia F, Recovery and treatment of Spirulina platensis cells cultured in a continuous photobioreactor to be used as food. Process Biochem 37:535-47 (2001). 
113. Rai PK, and Tripathi BD, Removal of heavy metals by the nuisance cyanobacteria Microcystis in continuous cultures: an eco-sustainable technology. Environ Sci 4:53-9 (2007).

114. Sassano CEN, Gioielli LA, Almeida KA, Sato S, Perego P, Converti A, and Carvalho JCM, Cultivation of Spirulina platensis by continuous process using ammonium chloride as nitrogen source. Biomass and Bioenergy 31:593-8 (2007).

115. Tredici MR, and Materassi R, From open ponds to vertical alveolar panels: the Italian experience in the development of reactors for the mass cultivation of phototrophic microorganisms. J Appl Phycol 4:221-31 (1992).

116. Chojnacka K, and Noworyta A, Evaluation of Spirulina sp. growth in photoautotrophic, heterotrophic and mixotrophic cultures. Enzyme Microb Technol 34:461-5 (2004).

117. Yuan S, Zhou X, Chen R, and Song B, Study on modelling microalgae growth in nitrogen-limited culture system for estimating biomass productivity. Renew Sustain Energy Rev 34:525-35 (2014).

118. Zhang XW, Zhang YM, and Chen F, Application of mathematical models to the determination optimal glucose concentration and light intensity for mixotrophic culture of Spirulina platensis. Process Biochem 34:477-81 (1999).

119. Lee D-Y, and Rhee GY, Kinetics of growth and death in Anabaena flos-aquae (cyanobacteria) under light limitation and supersaturation. J Phycol 35:700-9 (1999).

120. Shi XM, Zhang XW, and Chen F, Heterotrophic production of biomass and lutein by Chlorella protothecoides on various nitrogen sources. Enzyme Microb Technol 27:3128 (2000).

121. Lu C, Chi Mei Lee, Wei Ming Lu, and Chen PC, A model of nitrogen removal in waste-waters using alginate-entrapped cyabobacteria Anabaena Ch3. Environ Int 20:529-40 (1994).

122. Ruiz J, Arbib Z, Álvarez-Díaz PD, Garrido-Pérez C, Barragán J, and Perales JA, Photobiotreatment model (PhBT): a kinetic model for microalgae biomass growth and nutrient removal in wastewater. Environ Technol 34:979-91 (2013).

123. Guven B, and Howard A, A review and classification of the existing models of cyanobacteria. Prog Phys Geogr 30 :1-24 (2006).

124. Wit R, Ende FP, and Gemerden H, Mathematical simulation of the interactions among cyanobacteria, purple sulfur bacteria and chemotrophic sulfur bacteria in microbial mat communities. FEMS Microbiol Ecol 17:117-36 (1995).

125. Dang TC, Fujii M, Rose AL, Bligh M, and Waite TD, Characteristics of the freshwater cyanobacterium Microcystis aeruginosa grown in iron-limited continuous culture. Appl Environ Microbiol 78:1574-83 (2012). 
126. Kapdan IK, and Aslan S, Application of the Stover-Kincannon kinetic model to nitrogen removal by Chlorella vulgaris in a continuously operated immobilized photobioreactor system. J Chem Technol Biotechnol 83:998-1005 (2008).

127. Cornet JF, Dussap CG, and Dubertret G, A structured model for simulation of cultures of the cyanobacterium Spirulina platensis in photobioreactors: I. Coupling between light transfer and growth kinetics. Biotechnol Bioeng 40:817-25 (1992).

128. Gorbunov MY, Kuzminov FI, Fadeev V V., Kim JD, and Falkowski PG, A kinetic model of non-photochemical quenching in cyanobacteria. Biochim Biophys Acta Bioenerg 1807:1591-9 (2011).

129. Cornejo PK, Zhang Q, and Mihelcic JR, Quantifying benefits of resource recovery from sanitation provision ina developing world setting. J Environ Manage 131:7-15 (2013).

130. Mo W, and Zhang Q, Energy-nutrients-water nexus: Integrated resource recovery in municipal wastewater treatment plants. J Environ Manage 127:255-67 (2013).

131. Novotny V, Water- energy nexus: retrofitting urban areas to achieve zero pollution. Build Res Inf 41:589-604 (2013).

132. Dai G-Z, Shang J-L, and Qiu B-S, Ammonia may play an important role in the succession of cyanobacterial blooms and the distribution of common algal species in shallow freshwater lakes. Glob Chang Biol 18:1571-81 (2012).

133. Latour D, and Giraudet H, Factors influencing the spatio-temporal distribution of benthic Microcystis aeruginosa colonies (Cyanobacteria) in the hypertrophic Grangent Reservoir (Loire, France). C R Biol 327:753-61 (2004).

134. Prajapati SK, Kaushik P, Malik A, and Vijay VK, Phycoremediation coupled production of algal biomass, harvesting and anaerobic digestion: possibilities and challenges. Biotechnol Adv 31:1408-25 (2013).

135. Heyer A, Andersson H, and Lundstrom K, Performance, carcass and technological meat quality of pigs in indoor and outdoor production systems. Acta Agric Scand A, Anim Sci 56 (2006).

136. Rosenfeld Y, Innovative construction methods. Constr Manag Econ 12:521-41 (1994).

137. Chanawongse L, Lee YK, Bunnag B, and Tanticharoen M, Productivity of the cyanobacterium Spirulina platensis in cultures using sunlight. Bioresour Technol 48:143-8 (1994).

138. Heuvelink E, Bakker MJ, Hogendonk L, Janse J, Kaarsemaker R, and Maaswinkel R, Horticultural lighting in the Netherlands: new developments. Acta Hortic (ISHS) 711:25-34 (2006). 
139. Borges MT, Silva P, Moreira L, and Soares R, Integration of consumer-targeted microalgal production with marine fish effluent biofiltration - A strategy for mariculture sustainability. J Appl Phycol 17:187-97 (2005).

140. Prikupets LB, and Tikhomirov AA, Optimization of lamp spectrum for vegetable growth, in Proceedings of the International Lighting in Controlled Environments Workshop (NASA-CP-95-3309), ed. Tibbitts TW, University of Wisconsin, pp 31 (1994).

141. Brennan D, Identification of Waste in Utility Systems, in Sustainable process engineering: concepts, strategies, evaluation and implementation, Pan Stanford Publishing, Signapore, pp 103-31 (2013).

142. Brennan D, Energy Conservation, in Sustainable process engineering: concepts, strategies, evaluation and implementation, Pan Stanford Publishing, Singapore, pp 133-51 (2013).

143. Atkinson S, Organic acid recovery through bipolar membrane electrolysis. $\mathrm{Membr}$ Technol 1996:2 (1996).

144. Sydney EB, Sturm W, de Carvalho JC, Thomaz-Soccol V, Larroche C, Pandey A, and Soccol CR, Potential carbon dioxide fixation by industrially important microalgae. Bioresour Technol 101:5892-6 (2010).

145. Vetayasuporn S, The Potential for Using Wastewater from Household Scale Fermented Thai Rice Noodle Factories for Cultivating Spirulina platensis. Pakistan J Biol Sci 7:1554-8 (2004).

146. Mata TM, Melo AC, Simões M, and Caetano NS, Parametric study of a brewery effluent treatment by microalgae Scenedesmus obliquus. Bioresour Technol 107:151-8 (2012).

147. Raposo MF de J, Oliveira SE, Castro PM, Bandarra NM, and Morais RM, On the utilization of microalgae for brewery effluent treatment and possible applications of the produced biomass. J Inst Brew 116:285-92 (2010).

148. Ummalyma SB, and Sukumaran RK, Cultivation of microalgae in dairy effluent for oil production and removal of organic pollution load. Bioresour Technol 165:295-301 (2014).

149. Canizares RO, Dominguez AR, Rivas L, Montes MC, Travieso L, and Benitez F, Free and immobilized cultures of spirulina-maxima for swine waste treatment. Biotechnol Lett 15:321-6 (1993).

150. Cañizares RO, and Domínguez AR, Growth of Spirulina maxima on swine waste. Bioresour Technol 45:73-5 (1993).

151. Dunn K, Rose P, and Maart B, Arthrospira (Spirulina) in tannery wastewaters. Part 2: Evaluation of tannery wastewater as production media for the mass culture of Arthrospira biomass. Water SA 39:271-8 (2013). 
152. Chan A, Use of Microalgae in Wastewater Treatment to Remove Contaminants and Purify Biogas, University of Guelph, (2011).

153. Cho S, Luong TT, Lee D, Oh YK, and Lee T, Reuse of effluent water from a municipal wastewater treatment plant in microalgae cultivation for biofuel production. Bioresour Technol 102:8639-45 (2011).

154. Olguín EJ, Dual purpose microalgae-bacteria-based systems that treat wastewater and produce biodiesel and chemical products within a Biorefinery. Biotechnol Adv 30:1031-46 (2012).

155. El-Bestawy E, Treatment of mixed domestic-industrial wastewater using cyanobacteria. J Ind Microbiol Biotechnol 35:1503-16 (2008).

156. Pandit S, Nayak BK, and Das D, Microbial carbon capture cell using cyanobacteria for simultaneous power generation, carbon dioxide sequestration and wastewater treatment. Bioresour Technol 107:97-102 (2012).

157. Arata S, Strazza C, Lodi A, and Del Borghi A, Spirulina platensis Culture with Flue Gas Feeding as a Cyanobacteria-Based Carbon Sequestration Option. Chem Eng Technol 36:91-7 (2013).

158. Kumar K, Dasgupta CN, Nayak B, Lindblad P, and Das D, Development of suitable photobioreactors for $\mathrm{CO}_{2}$ sequestration addressing global warming using green algae and cyanobacteria. Bioresour Technol 102:4945-53 (2011).

159. Vonshak A, Microalgal biotechnology: is it an economic success? In: DaSilva E, Ratledge C, Sasson A, editors. Biotechnology: economic and social aspects Issues for Developing Countries Cambridge: Cambridge University Press; p. 70-80 (1992).

160. Li J, Zhu D, Niu J, Shen S, and Wang G, An economic assessment of astaxanthin production by large scale cultivation of Haematococcus pluvialis. Biotechnol Adv 29:568-74 (2011). 


\section{List of Figures}

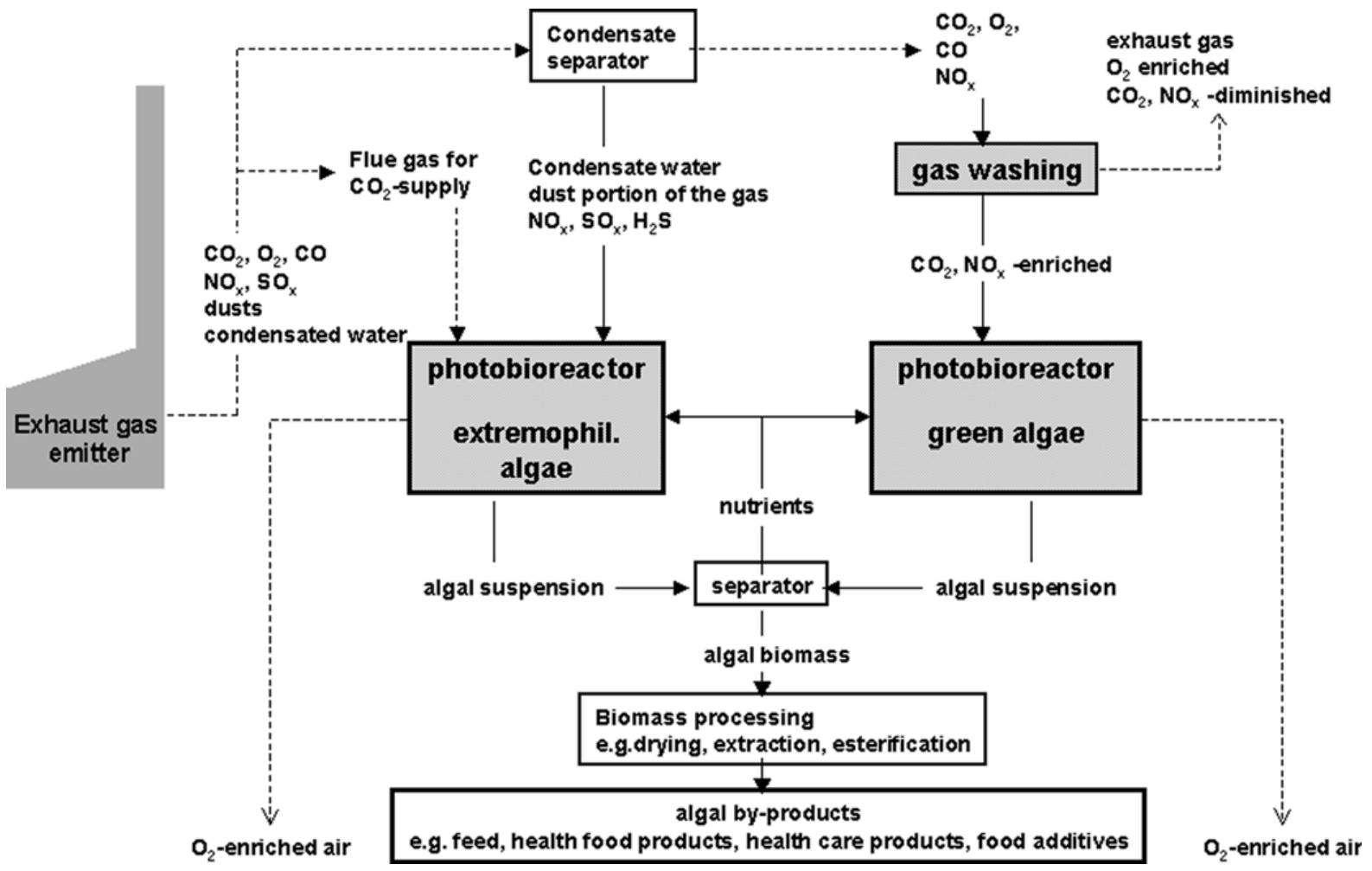

Figure 1: Scheme for $\mathrm{CO}_{2}$ fixation from industrial exhaust gas by microalgae (Pulz and Gross $^{65}$, reprinted from Applied Microbiology and Biotechnology (2004), vol. 65(6), pp. 635-648, with kind permission from Springer Science and Business Media, CCC licence $3623800818054)$ 


\section{List of Tables}

Table 1: Identified Nutraceutical Functions of C-phycocyanin and Applications of Its Fluorescent Properties

\begin{tabular}{ll}
\hline Nutraceutical Functions & Reference \\
\hline $\begin{array}{l}\text { Inhibits growth of leukemia cells. } \\
\text { Lowers blood lipid, combating fatigue and increases the level of } \\
\text { immunoglobulin A (IgA) and immunoglobulin M (IgM). }\end{array}$ & 34 \\
Nephroprotection, antioxidant activity, metal chelation, neuroprotection. & 35 \\
$\begin{array}{l}\text { Slows cancer progression, prevents atherosclerosis development, improves } \\
\text { blood lipid profile, reduces allergic inflammation and protects against hay- } \\
\text { fever. }\end{array}$ & 36 \\
$\begin{array}{l}\text { Promising anti-fungal and anti-viral activity. } \\
\text { Potent free-radical scavenging ability. }\end{array}$ & 37 \\
$\begin{array}{l}\text { Increases the expression of essential enzymes and biochemicals related to the } \\
\text { balanced function of liver and kidney, leading to the improved detoxification. }\end{array}$ & 39,40 \\
\hline
\end{tabular}

\section{Applications of Fluorescent Properties}

\section{Reference}

Superior fluorescent dye for medical tagging.

41

$42,43,44,45,46,47,48,49,50$

Method of monitoring potentially harmful cyanobacterial populations in native environs.

Fluorescent label for immunoassay.

Use as fluorescent tags in histochemistry and reactive oxygen species assay.

Electrophoretic application in monitoring protein blotting and the focusing time of protein samples during isoelectric focusing.

Determination of phycobiliprotein composition of marine and freshwater picophytoplankton in oligotrophic environments.

Monitoring influence of protein encapsulation and studying matrix and protein interaction and stability of protein in silica matrix of Phycocyanindoped silica biomaterials.

Fluorescence emitter in fluorescence-activated cell sorting flow cytometry. 56 
Table 2: Summary of Optimal Phycocyanin Productivity by Microalgal Species and Respective Bioreactor Parameters

\begin{tabular}{|c|c|c|c|c|c|c|c|c|c|}
\hline \multirow[t]{2}{*}{ Species } & \multicolumn{3}{|c|}{ Lighting Conditions } & \multicolumn{2}{|c|}{$\begin{array}{l}\text { Climatic } \\
\text { Conditions }\end{array}$} & \multicolumn{2}{|l|}{ Media } & \multirow{2}{*}{$\begin{array}{l}\text { Phycocyanin } \\
\text { Productivity } \\
\text { Maximal } \\
\text { transient }\left(\mathrm{g} \cdot \mathrm{L}^{-}\right. \\
\left.1 \cdot \mathrm{d}^{-1}\right)\end{array}$} & \multirow[t]{2}{*}{ Reference } \\
\hline & $\begin{array}{l}\text { Spectrum/Q } \\
\text { uality }\end{array}$ & $\begin{array}{l}\text { Light } \\
\text { Intensity }\end{array}$ & $\begin{array}{l}\text { Light Cycle } \\
\text { (day:night } \\
\text { hours) }\end{array}$ & $\mathrm{pH}$ & $\begin{array}{l}\text { Temp } \\
\left({ }^{\circ} \mathrm{C}\right)\end{array}$ & Type & $\begin{array}{l}\text { Modificatio } \\
\mathrm{n}\end{array}$ & & \\
\hline \multirow[t]{7}{*}{ A. platensis } & $\begin{array}{l}\text { Fluorescent } \\
\text { white }\end{array}$ & $\begin{array}{l}700 \\
\mu \mathrm{mol} / \mathrm{m}^{2} / \mathrm{s}\end{array}$ & $N R$ & 9 & 30 & Unique & $\begin{array}{l}\mathrm{NaNO}_{3} \\
0.045 \mathrm{M} \\
\text { (initial) }\end{array}$ & 0.13 & 66 \\
\hline & $\begin{array}{l}\text { Red filtered } \\
\text { sunlight }\end{array}$ & $\begin{array}{l}800 \operatorname{lux}(\sim 15 \\
\left.\mu \mathrm{mol} / \mathrm{m}^{2} / \mathrm{s}\right)\end{array}$ & $12: 12$ & $\begin{array}{l}8.5- \\
9.5\end{array}$ & 25.3 & $\begin{array}{l}\text { Diluted } \\
\text { Zarrouks }\end{array}$ & $\begin{array}{l}\text { Diluted to } \\
20 \%\end{array}$ & $0.01^{\mathrm{a}}$ & 67 \\
\hline & $\begin{array}{l}\text { Fluorescent } \\
\text { white }\end{array}$ & $\begin{array}{l}200 \\
\mu \mathrm{mol} / \mathrm{m}^{2} / \mathrm{s}\end{array}$ & $14: 10$ & 9 & 30 & Zarrouks & None & $0.07^{\mathrm{a}}$ & 68 \\
\hline & $\begin{array}{l}\text { Fluorescent } \\
\text { white }\end{array}$ & $\begin{array}{l}8-18 \mathrm{~W} / \mathrm{m}^{2} \\
(\sim 37-83 \\
\left.\mu \mathrm{mol} / \mathrm{m}^{2} / \mathrm{s}\right)\end{array}$ & $N R$ & 9.5 & 36 & $\begin{array}{l}\mathrm{NO}^{3-} \\
\text { reduced } \\
\text { Zarrouks }\end{array}$ & $\begin{array}{l}\mathrm{NO}^{3-} 0.29 \\
\mathrm{~g} / \mathrm{L}\end{array}$ & $0.008^{\mathrm{a}}$ & 69 \\
\hline & Fluorescent & $\begin{array}{l}160 \\
\mu \mathrm{mol} / \mathrm{m}^{2} / \mathrm{s}\end{array}$ & $24: 0$ & $\begin{array}{l}9.5- \\
10.5\end{array}$ & 30 & $\begin{array}{l}\text { Modified } \\
\text { Zarrouks }\end{array}$ & $\begin{array}{l}0.5-2 \mathrm{~g} / \mathrm{L} \\
\text { glucose }\end{array}$ & $0.07^{\mathrm{a}}$ & 70 \\
\hline & Red LED & $\begin{array}{l}3000 \\
\mu \mathrm{mol} / \mathrm{m}^{2} / \mathrm{s}\end{array}$ & $24: 0$ & $N R$ & 30 & Zarrouks & None & $0.02^{\mathrm{a}}$ & 71 \\
\hline & $\begin{array}{l}\text { Fluorescent } \\
\text { white }\end{array}$ & $\begin{array}{l}80-120 \\
\mu \mathrm{mol} / \mathrm{m}^{2} / \mathrm{s}\end{array}$ & $24: 0$ & 9.5 & 30 & $\begin{array}{l}\text { Modified } \\
\text { Zarrouks }\end{array}$ & $\begin{array}{l}2 \mathrm{~g} / \mathrm{L} \\
\mathrm{glucose}+ \\
0.2 \mathrm{~g} / \mathrm{min} \\
\text { glucose } \\
\text { after } 5^{\text {th }} \text { day }\end{array}$ & $0.10^{\mathrm{a}}$ & 72 \\
\hline $\begin{array}{l}\text { Anabaena sp. } \\
\text { PCC } 7120\end{array}$ & $\begin{array}{l}\text { Fluorescent } \\
\text { white }\end{array}$ & $\begin{array}{l}110 \\
\mu \mathrm{mol} / \mathrm{m}^{2} / \mathrm{s}\end{array}$ & $12: 12$ & $\begin{array}{l}8- \\
11\end{array}$ & 28 & $\begin{array}{l}\text { BG11 with } \\
\text { HEPES } \\
\text { buffer }\end{array}$ & $\begin{array}{l}20 \mathrm{mM} \\
\text { HEPES } \\
\text { buffer }\end{array}$ & $0.02^{\mathrm{a}}$ & 73 \\
\hline $\begin{array}{l}\text { G. sulphuraria } \\
074 G\end{array}$ & No light & No light & No light & 2 & 42 & Unique & $\begin{array}{l}50-150 \mathrm{~g} / \mathrm{L} \\
\text { glucose }+ \\
1.38 \mathrm{~L} / \text { day } \\
\text { glucose } \\
\text { sol'n, } 50 \mathrm{~g} / \mathrm{L} \\
\mathrm{NH}_{4} \text { initial }\end{array}$ & 0.86 & 74 \\
\hline G. sulphureum & $\begin{array}{l}\text { Cool white } \\
\text { fluorescent }\end{array}$ & $\begin{array}{l}1000 \operatorname{lux}(\sim 14 \\
\left.\mu \mathrm{mol} / \mathrm{m}^{2} / \mathrm{s}\right)\end{array}$ & $16: 8$ & 8- 9 & 30 & $\begin{array}{l}\text { Modified } \\
\text { Zarrouks }\end{array}$ & $\begin{array}{l}\mathrm{NaNO}_{3} 3.5 \\
\mathrm{~g}, \mathrm{Na}_{2} \mathrm{CO}_{3} \\
6.24 \mathrm{~g} / \mathrm{L}\end{array}$ & $0.005^{\mathrm{a}}$ & 75 \\
\hline $\begin{array}{l}\text { Phormidium } \\
\text { ceylanicum }\end{array}$ & $\begin{array}{l}\text { Fluorescent } \\
\text { white }\end{array}$ & $\begin{array}{l}130 \\
\mu \mathrm{mol} / \mathrm{m}^{2} / \mathrm{s}\end{array}$ & $12: 12$ & 7.4 & 27 & BG11 & $\begin{array}{l}\text { Optimized } \\
\mathrm{NaNO}_{3} \text {, } \\
\mathrm{CaCl}_{3} \text {, citric } \\
\text { acid, trace } \\
\text { metals. }\end{array}$ & $0.02^{\mathrm{a}}$ & 76 \\
\hline $\begin{array}{l}\text { Synechococcus } \\
\text { sp. NKBG } \\
042903\end{array}$ & $\begin{array}{l}\text { Red LED } \\
(660 \mathrm{~nm} \\
\text { peak })\end{array}$ & $55 \mu \mathrm{mol} / \mathrm{m}^{2} / \mathrm{s}$ & $24: 0$ & $N R$ & 25 & $\begin{array}{l}\text { BG11 with } \\
\text { NaCL }\end{array}$ & $\begin{array}{l}30 \mathrm{~g} / \mathrm{L} \\
\mathrm{NaCL}\end{array}$ & 0.023 & 77 \\
\hline
\end{tabular}

NR: Information was not recorded in relevant literature

${ }^{\text {a }}$ Calculated values 
Table 3: Summary of Bioreactor Configurations and Parameters for Optimal Phycocyanin Productivity

\begin{tabular}{|c|c|c|c|c|c|c|c|}
\hline $\begin{array}{l}\text { Operational } \\
\text { Mode }\end{array}$ & Geometry & Agitation & Forced Aeration & Growth Period $^{b}$ & $\begin{array}{l}\text { Microalgal } \\
\text { Species }\end{array}$ & $\begin{array}{l}\text { Maximal } \\
\text { Transient } \\
\text { Phycocyanin } \\
\text { Productivity } \\
\left(\mathrm{g} \cdot \mathrm{L}^{-1} \cdot \mathrm{d}^{-1}\right)\end{array}$ & Reference \\
\hline Batch & Flat-type (1 L) & $300 \mathrm{rpm}$ & $\begin{array}{l}2.5 \% \mathrm{CO}_{2}, 0.2 \mathrm{vvm}, \\
\text { (80-100 um diffusion) }\end{array}$ & $N R$ & A. platensis & 0.13 & 66 \\
\hline Batch & $\begin{array}{l}\text { Flat-type } \\
(500 \mathrm{~mL})\end{array}$ & Gas sparging & Air, $1 \mathrm{vvm}$ & 2 days & $\begin{array}{l}\text { Synechococcus } \\
\text { sp. } N K B G \\
042903\end{array}$ & 0.023 & 77 \\
\hline Batch & $\begin{array}{l}\text { Conical Flask } \\
(250 \mathrm{~mL})\end{array}$ & $\begin{array}{l}\text { Continuous } \\
\text { orbital shaker }\end{array}$ & None & 15 days & G. sulphureum & $0.005^{\mathrm{a}}$ & 75 \\
\hline Batch & $\begin{array}{l}\text { Open Tank } \\
(50 \mathrm{~L})\end{array}$ & $N R$ & Air, $0.03 \mathrm{vvm}$ & 18 days & A. platensis & $0.01^{\mathrm{a}}$ & 67 \\
\hline Batch & $\begin{array}{l}\text { Conical Flask } \\
(250 \mathrm{~mL})\end{array}$ & $N R$ & None & 32 days & $\begin{array}{l}\text { Phormidium } \\
\text { ceylanicum }\end{array}$ & $0.02^{\mathrm{a}}$ & 76 \\
\hline Batch & $\begin{array}{l}\text { Custom } \\
\text { Photobioreactor } \\
\left(\sim 275 \mathrm{~mL}^{\mathrm{a}}\right)\end{array}$ & Gas sparging & $\begin{array}{l}20 \mathrm{mM} / \mathrm{L} / \text { day } \\
\text { intermittent } \mathrm{CO}_{2}+0.1 \\
\mathrm{~L} / \mathrm{min} \text { continuous air }\end{array}$ & 6 days & A. platensis & $0.07^{\mathrm{a}}$ & 68 \\
\hline Batch & $\begin{array}{l}\text { Parallelepipedic } \\
(4 \mathrm{~L})\end{array}$ & $N R$ & Air, $1.6 \times 10^{-5} \mathrm{Nm}^{3} / \mathrm{s}$ & 11.2 days $^{\mathrm{a}}$ & A. platensis & $0.008^{\mathrm{a}}$ & 69 \\
\hline Batch & $\begin{array}{l}\text { Conical Flask } \\
(500 \mathrm{~mL})\end{array}$ & $120 \mathrm{rpm}$ & None & 4 days & A. platensis & $0.02^{\mathrm{a}}$ & 71 \\
\hline Continuous & $\begin{array}{l}\text { Bioreactor } \\
(3 \mathrm{~L})\end{array}$ & $500 \mathrm{rpm}$ & $2.5 \mathrm{~L} / \mathrm{min}$ air & 1.38 L/day & $\begin{array}{l}\text { G. sulphuraria } \\
074 G\end{array}$ & 0.86 & 74 \\
\hline Fed-Batch & $\begin{array}{l}\text { Conical Flask } \\
(250 \mathrm{ml})\end{array}$ & $N R$ & $\begin{array}{l}0.03 \% \mathrm{CO}_{2}, 45 \mu \mathrm{m} \\
\text { filtered (flow rate } N R \text { ) }\end{array}$ & 10 days & $\begin{array}{l}\text { Anabaena sp. } \\
\text { PCC } 7120\end{array}$ & $0.02^{\mathrm{a}}$ & 73 \\
\hline Fed-batch & $\begin{array}{l}\text { Fermentor } \\
(3.7 \mathrm{~L})\end{array}$ & $300 \mathrm{rpm}$ & Sterile air, $100 \mathrm{~L} / \mathrm{h}$ & 12.5 days & A. platensis & $0.07^{\mathrm{a}}$ & 70 \\
\hline Fed-Batch & $\begin{array}{l}\text { Bioreactor } \\
(3.7 \mathrm{~L})\end{array}$ & $300 \mathrm{rpm}$ & Sterile air, $100 \mathrm{~L} / \mathrm{h}$ & 7 days & A. platensis & $0.10^{\mathrm{a}}$ & 72 \\
\hline
\end{tabular}

${ }^{\mathrm{a}}$ Calculated values.

${ }^{b}$ Growth Period is recorded at maximal transient phycocyanin productivity.

NR: Information was not recorded in relevant literature. 
Table 4: Summary of Optimal Conditions for Phycocyanin Production in Dedicated Systems

- $\quad$ Mixotrophy (autotrophs + heterotrophs).

- Polyculture (multiple metabolisms, symbiotic toxin-generating species).

- High light intensity (up to system specific limit) with maximum emission wavelength near $620 \mathrm{~nm}$.

- Temperature dependent on native climate of species

- Optimal pH is typically, though not exclusively, situated in the range where bicarbonate speciation of dissolved inorganic carbon dominates (i.e. <10.5).

- Nitrogen supply in the form of ammonium, with care not to induce substrate inhibition.

- Added $\mathrm{CO}_{2}$ has limited effect, especially if acidification is not controlled.

- Sodium carbonate additions are beneficial.

- Citric acid supplementation to growth medium.

- Continuous reactor, designed to use air sparging (possibly enriched with $\mathrm{CO}_{2}$ up to few vol\%) for mixing/circulation and for deoxygenation. 